\title{
Políticas públicas y apoyo político en el Estado de las Autonomías
}

Manuel Tamayo* y Ernesto Carrillo**

Palabras clave: Apoyo politico, politicas públicas, resultados de politica pública, procedimientos de gobierno.

\section{Introducción}

La cuestión del apoyo político es uno de los temas más recurrentes de la Ciencia Política. Desde que Easton escribiera A System Analysis of Political Life en 1965 hasta la actualidad, se ha acumulado un importante volumen de conocimiento sobre el apoyo político que incluye conceptos, hipótesis básicas, teorías, estrategias de indagación y análisis empíricos sobre la evolución del apoyo político y los factores que influyen en el mismo ${ }^{1}$. Una de las conclusiones que se extrae de la revisión de la literatura es que se trata de un tema muy complejo debido a la existencia de diversos objetos políticos hacia los que se puede expresar el apoyo y como consecuencia también de la concurrencia de múltiples factores que influyen sobre el apoyo político desde cuestiones macro, como por ejemplo, el diseño político e institucional, hasta aspectos micro, como las características socio-demográficas y psicológicas de los individuos, entre otras.

La cuestión de la influencia de las políticas sobre el apoyo político, también forma parte desde hace bastante tiempo de la agenda de investigación de los estudios de políticas públicas (Dye 1966) y del repertorio de factores que contribuyen a las fluctuaciones en el apoyo político (Wahlke 1971; Miller 1974a). Es precisamente en este ámbito de la acción pública en el que se inscribe este trabajo, concretamente, se intenta ofrecer una respuesta a la siguiente pregunta: ¿en qué medida y cómo influyen las políticas públicas sobre el apoyo político? El apoyo político es, por tanto, nuestra variable dependiente y las políticas públicas la variable independiente. La indagación se resuelve, modestamente, tomando un número de objetos políticos limitados, todos ellos referidos

* Profesor Contratado Doctor de Ciencia Politica y de la Administración de la Universidad Rey Juan Carlos.

** Profesor Titular de Ciencia Política y de la Administración de la Universidad Complutense de Madrid.

1 Por mencionar algunas de las obras colectivas sobre este tema publicadas en los últimos diez años véanse los trabajos compilados por Kaase y Newton (1995); Klingemann y Fuch, (1995); Deth y Scarbrough (1995); Borre y Scarbrough (1995); Niedermayer y Sinnott (1995); Nye, Zelikow y King (1997); Norris (1999); Pharr y Putnam (2000); Hibbing y Theiss-Morse (2001a). A todo ello habría que añadir un importante volumen de artículos, algunos de los cuales se recogen en la bibliografía.

${ }_{2}^{2}$ Dye mencionaba, ya en 1966, algunas preguntas que la investigación sobre los resultados de las políticas públicas debería intentar responder: ¿Qué consecuencias tienen los resultados de las políticas sobre el apoyo ofrecido al sistema político? ¿Qué demandas deben satisfacerse con objeto de mantener el nivel de apoyo necesario que permita persistir al sistema? ¿En qué medida las adhesiones al sistema proporcionan el apoyo necesario para que el sistema pueda persistir, incluso ante resultados de política pública insatisfactorios? 
a diversos aspectos del Estado de las autonomías, considerando únicamente dos dimensiones de las políticas públicas, las percepciones sobre sus resultados y sobre los procedimientos a través de los cuales se elaboran, y todo ello para una fecha concreta, el año 2002. ${ }^{3}$

En cuanto a los tipos de objetos políticos analizados seguimos la propuesta formulada por Norris (1999) distinguiendo entre la comunidad política, los principios del régimen, el rendimiento del régimen, las instituciones del régimen y los actores políticos. Asumimos la hipótesis de que los ciudadanos son capaces de expresar sus apoyos de forma distinta a los diferentes objetos políticos (Dalton 1999). Asimismo, partimos de la distinción entre apoyo difuso y específico ubicando, como hace Norris (1999), a la comunidad política como punto de máximo apoyo difuso y a los actores políticos como punto de máximo apoyo específico dentro de un continuo en el que se localizarían los restantes objetos políticos arriba mencionados. Los objetos políticos considerados son: la identificación con la comunidad autónoma, las preferencias por las formas de organización territorial del Estado, la satisfacción con el funcionamiento del Estado de las autonomías, la valoración de las instituciones -concretamente del parlamento y del gobierno autonómico- y la valoración del presidente autonómico en ejercicio ${ }^{4}$.

En cuanto a las políticas vamos a centrar nuestra atención, principalmente, en la influencia que ejerce sobre el apoyo político los resultados y el proceso de elaboración de las políticas ${ }^{5}$.

Dado que sobre el apoyo político influyen otros factores, además de los aquí contemplados, se ha optado por utilizar, cuando nos ha sido posible, esos otros factores como variables de control, de tal forma que podamos aislar el impacto directo de las políticas públicas. Nos referimos tanto a variables micro, relativas a las características socio-demográficas, valores y comportamientos de los ciudadanos, como a aquellas otras de carácter macro, concernientes al entorno económico y social de los sistemas políticos y el diseño institucional de estos.

La hipótesis principal que intentaremos demostrar es que la dimensión de las políticas públicas que más influye sobre el apoyo a las autoridades en ejercicio y a las instituciones es el procedimiento con el que se elaboran las políticas, siendo la cuestión del «cómo se gobierna» un asunto más importante que los propios resultados percibidos de las políticas. Para intentar demostrar esta hipótesis hemos recurrido a una fuente, el estudio de Instituciones y Autonomias II elaborado por el Centro de Investigaciones Sociológicas en 1998 y 2002, en la que se recoge información bastante completa en lo que respecta tanto al apoyo político como a las políticas públicas

Además de esta introducción, el trabajo consta de tres epígrafes y unas conclusiones. En el primer epígrafe se aborda, brevemente, el estado de la cuestión sobre los estudios de apoyo político, poniendo un énfasis especial en la influencia ejercida por las políticas públicas. En el segundo, se presenta la metodología y los modelos estadísticos empleados. En el tercero, se describen los resultados obtenidos.

${ }^{3}$ En un trabajo previo presentado al III Seminario de Investigación del Departamento de Ciencia Política y de la Administración II, de la Facultad de Ciencias Políticas y Sociología de la Universidad Complutense de Madrid, se incluyó también el año 1998, que aquí se evita dado que las diferencias observables entre un año y otro son muy reducidas.

${ }_{4}$ Para un análisis sobre la evolución de estos y otros indicadores véase Montero y Torcal (1990) y Mota (1998). Por otra parte, Mota y Subirats (2000) y Mota (2002) han abordado la influencia ejercida por el capital social y la gobernabilidad sobre el apoyo político a nivel autonómico, manejando datos agregados de la misma fuente que emplearemos en este estudio.

${ }^{5}$ En trabajos anteriores hemos insistido tanto desde un punto de vista teórico (Bañón y Carrillo 1997) como empírico (Carrillo 199697; Bazaga Carrillo, Sosa, Tamayo 1998; Carrillo, Tamayo, Pino, Bazaga 2000; Carrillo y Tamayo 2002) en este mismo asunto en lo relativo a la legitimidad de la Administración pública. 


\section{Marco conceptual}

\section{A) El concepto de apoyo político utilizado}

En esta investigación, como en muchas otras que han analizado la cuestión del apoyo político, se ha optado por seguir de la manera más fiel posible el esquema conceptual desarrollado por Easton $(1965,1975)^{6}$. De acuerdo con la definición de este autor «decimos que A apoya a B cuando A actúa en favor de B o cuando se orienta de forma favorable hacia B. B puede ser una persona o un grupo o también una meta, idea o institución» (Easton 1965). El apoyo puede consistir, pues, tanto en comportamientos observables como en un conjunto de actitudes o predisposiciones para actuar a favor de alguien o de algo. Es en este segundo ámbito de las actitudes en el que hemos centrado nuestra atención.

Easton diferencia entre tres objetos de apoyo político: la comunidad política, el régimen y las autoridades ${ }^{7}$. Asimismo, distingue entre dos tipos de apoyo: el específico y el difuso. «El apoyo específico tiene las siguientes propiedades: se dirige hacia las autoridades políticas y las instituciones con autoridad ${ }^{8}$; presupone que los miembros son capaces de asociar la satisfacción y la insatisfacción con el comportamiento percibido de las autoridades, ya adquiera el comportamiento la forma de acciones identificables o de algún tipo de rendimiento general atribuido a las autoridades; el apoyo específico es posible sólo bajo una cultura en la que los miembros abrigan la noción de que las autoridades pueden ser las responsables de lo que sucede en la sociedad; finalmente, este tipo de apoyo varía con los beneficios o satisfacciones percibidos, cuando éstos descienden o cesan el apoyo también lo hace» (Easton 1975).

Como señala este mismo autor, «el modo más sintético de describir el significado primario de apoyo difuso sería diciendo que hace referencia a las evaluaciones de lo que un objeto es o representa y no a lo que hace. Consiste en una reserva de actitudes favorables o de buena voluntad que facilitan que los miembros acepten o toleren los outputs a los que se oponen o los efectos que ellos perciben como perjudiciales para sus deseos» (Easton 1975). Se trata de un tipo de apoyo más duradero que el específico, que subyace al régimen en su conjunto y a la comunidad política, y que «proviene de la socialización de los individuos -tanto en su infancia como en la etapa adulta- así como de la experiencia directa» (Easton 1975). El apoyo difuso hacia las autoridades políticas y hacia el régimen se expresa típicamente en dos formas: la confianza y la creencia en la legitimidad de los objetos políticos. En el caso de la comunidad política puede adquirir diversas manifestaciones, como son el sentido de pertenencia, la conciencia común o la identificación de grupo (Easton 1975)9.

${ }^{6}$ En las líneas siguientes se traza una síntesis del concepto de apoyo y otras cuestiones planteadas por Easton. Aunque se trata de tesis de sobra conocidas, ha parecido no obstante oportuno recordarlas aquí para así poder entender mejor la lógica y los resultados de esta investigación.

Como señalara Easton, el apoyo político no está hecho de una sola pieza (1975) y la gravedad de las consecuencias de la falta de apoyo varía dependiendo del objeto político de que se trate. La clásica distinción entre el apoyo al sistema y el rechazo a las autoridades en ejercicio que se salda con la elección de nuevas autoridades es un ejemplo de ello. Para una comprobación empírica de carácter global -hasta donde permite la Encuesta Mundial de Valores- de cómo los ciudadanos distinguen los diversos objetos de apoyo político, véase Klingemann (1999).

${ }^{8}$ Siempre siguiendo a Easton (1975), con el concepto de autoridades se hace referencia a los miembros del ejecutivo, legislativo y judicial, así como a los empleados públicos de los diferentes grupos profesionales. Asimismo, se incluye las instituciones de las que forman parte estas autoridades, es decir, los distintos niveles de gobierno, los parlamentos, la administración de justicia, las administraciones públicas, etc.

${ }^{9}$ La vinculación del apoyo específico a los outputs y la relativa independencia, al menos en el corto plazo, del apoyo difuso respecto de los outputs permite, como es sabido, dotar de cierta estabilidad a los sistemas políticos. Las hipótesis sobre las relaciones entre legitimidad y eficacia que formulara Lipset (1959) años antes, operan de una forma parecida a la propuesta por Easton. Para una comprobación empírica en diversos contextos nacionales de estas cuestiones véanse Muller y Jukam (1977); Muller, Jukam y Seligson (1982); Finkel, Muller y Seligson (1989). 
En el supuesto de que se produzca una situación de confianza «los miembros del sistema político considerarán que sus intereses serán atendidos incluso en el caso de que las autoridades estén sometidas a una reducida supervisión o escrutinio». En lo que respecta al régimen la confianza se expresaría como la «satisfacción simbólica con el procedimiento a través del cual se dirige el país». El contrario de la confianza sería la desconfianza o cinismo político ${ }^{10}$ (Easton 1975).

Según Easton la legitimidad es «la convicción de lo que es correcto y apropiado para aceptar y obedecer a las autoridades y para respetar las exigencias del régimen. Esto refleja el hecho de que, de una forma más o menos vaga o explícita, una persona ve a los objetos como algo conforme a sus propios principios morales y a su sentido de lo que es correcto y apropiado en la esfera política» (1975). El concepto de legitimidad se puede aplicar tanto a la comunidad, como al régimen o a las autoridades.

\section{B) La influencia del performance sobre el apoyo político.}

De lo anterior se deduce que la influencia de las políticas sobre el apoyo político deberá observarse con mayor intensidad en determinados objetos políticos, concretamente en las instituciones y las autoridades en ejercicio, mientras que en los referidos a los principios del régimen y la comunidad política su influencia tenderá a ser, al menos en el corto plazo, prácticamente nula o sensiblemente inferior.

De hecho, las investigaciones disponibles respecto a las naciones desarrolladas muestran la existencia de unos elevados, cuando no además crecientes, niveles de apoyo a la democracia mientras que, al mismo tiempo, los ciudadanos se vuelven más exigentes y críticos con las instituciones y las autoridades en ejercicio.

Para intentar explicar esta pauta se han esgrimido muy diversos motivos. Uno de los más reiterados tiene que ver con el performance de las instituciones políticas. Concretamente Orren (1997) señala que la satisfacción, o la insatisfacción, con el gobierno ${ }^{11}$ no depende tanto de factores externos al propio gobierno, como de lo que éste hace. Hay que buscar pues, en la percepción de sus actuaciones, buena parte de la pérdida de la confianza en las instituciones y autoridades que se ha observado en diversas naciones desarrolladas. Para este autor la satisfacción de los ciudadanos con el gobierno es una razón integrada por dos términos: las percepciones sobre el gobierno y las expectativas de los ciudadanos.

$$
\text { Satisfacción }=(\text { percepciones sobre el gobierno } / \text { expectativas de los ciudadanos })^{12} \text {. }
$$

Sobre las percepciones del gobierno pueden influir diversos factores -por ejemplo, la denuncia del gobierno que realizan los medios de comunicación y los líderes políticos, u otros de más largo alcance, como el cam-

\footnotetext{
${ }^{10}$ Habría que distinguir dos usos frecuentes en la literatura del término confianza: uno, la confianza que se expresa hacia autoridades concretas en ejercicio, que guarda relación con el apoyo específico; y otro, la confianza que se expresa hacia los roles de autoridad. Es a este último uso al que se refiere Easton y que tiene que ver con el apoyo difuso. Igualmente hay que distinguir el rendimiento general atribuido a las autoridades -que forma parte del apoyo específico- de la satisfacción simbólica con el proceso por el que se dirige el país - vinculada al apoyo difuso-(Easton 1975).

${ }^{11}$ Este autor utiliza el término gobierno, como es frecuente en la literatura anglosajona, para referirse al conjunto de las instituciones políticas y no solo a las del ejecutivo.

${ }_{12}$ Así, si las percepciones sobre el gobierno son iguales o superiores a las expectativas el valor hipotético de esta razón será 1 o mayor, produciéndose una situación de satisfacción con el gobierno. Si por el contrario las expectativas son más elevadas que las percepciones el valor de la ratio será inferior a 1 y hablaremos de insatisfacción con el gobierno. El crecimiento en la insatisfacción con el gobierno pude deberse a diversas causas: una disminución de las percepciones favorables hacia el gobierno, un incremento en las expectativas ciudadanas, o ambas cosas a la vez.
} 
bio cultural en un sentido postmaterialista-; sin embargo, hay un factor que merece la pena subrayar que es el performance del gobierno. Orren reserva este término para referirse a tres tipos de acción gubernamental que pueden producir insatisfacción.

- La policy o las propias políticas públicas, esto es, el desacuerdo sobre alternativas de política pública concretas. La insatisfacción en este caso tendría su origen en el desajuste entre las preferencias de política pública de los ciudadanos y la percepción que tienen estos de las decisiones de política pública adoptadas por sus gobiernos. De modo que, las políticas adoptadas, pueden entrar en contradicción con las preferencias de política pública o con los principios ideológicos de los ciudadanos.

- El performance en sentido estricto, esto es, la evaluación sobre la eficacia de la acción de gobierno. La insatisfacción en este caso se debería a que los ciudadanos consideren que los gobiernos no están haciendo adecuadamente su trabajo. No se trata de debatir sobre alternativas de política pública sino de evaluar la habilidad del gobierno para resolver problemas de una manera eficaz y competente.

- La probity, o la evaluación sobre la integridad de los líderes políticos y del proceso político. Este último componente de las percepciones no tiene que ver, como los anteriores, con cuestiones sustantivas de las políticas públicas, sino con las procedimentales, de modo que en este caso la insatisfacción se debería a un desajuste entre las expectativas normativas de los ciudadanos sobre cómo deben elaborarse las políticas y los comportamientos observados de sus gobiernos ${ }^{13}$.

Cada una de estas dimensiones del performance entronca a su vez con otras tres líneas de investigación sobre la influencia de las políticas públicas en el apoyo político. La primera con los trabajos pioneros de Miller (1974 a y b) y la famosa polémica que mantuvo con Citrin (1974) a mediados de la década de 1970. A ello habría que añadir la larga serie de trabajos de estos y otros autores al respecto. La segunda arranca con la propuesta de Lane (1965) y continúa con toda la literatura sobre la influencia del performance económico sobre el apoyo político ${ }^{14}$. La tercera guarda relación inicialmente con los estudios psicosociales sobre la influencia de la justicia distributiva y procedimiental sobre el apoyo político, entre las que destacaría la obra de Tyler (véase Tyler y otros 1985 y 1997). A ello habría que añadir la literatura sobre la influencia de la corrupción en el apoyo político (entre otros Pharr 2000 y Porta 2000).

El otro término de la razón de satisfacción formulada por Orren es el relativo a las expectativas. De acuerdo con este autor, las expectativas estarían compuestas por deseos - esto es, los programas y servicios gubernamentales deseados- y las anticipaciones -la predicción de lo que es verosímil que el gobierno realice-. Según el autor, mientras que las expectativas en el sentido de deseo es posible que estén creciendo, las expectativas en el sentido de anticipación de las realizaciones del gobierno probablemente estén descendiendo ${ }^{15}$.

En este trabajo nos vamos a centrar, únicamente, en la influencia que ejercen sobre el apoyo político los resultados y los procedimientos, dejando al margen la cuestión de las preferencias de política pública.

${ }^{13}$ La distinción que establecen Hibbing y Theiss-Morse (2001b) entre policy outputs, policy outcomes y procedimientos responde a este mismo planteamiento de Orren. El interés del trabajo de aquellos es que realizan una muy buena demostración empírica para el caso de Los EEUU de América, mientras que el trabajo de Orren se limita a constatar el descenso en los valores de la escala de confianza política empleada en los American National Election Studies, sin entrar en el análisis empírico de la influencia de los diversos factores que menciona y, en especial, los relativos al performance.

${ }_{14}$ Sobre esta misma cuestión, sobresalen en lo relativo al caso español los trabajos de Maravall y Przeworski (1998).

${ }^{15}$ No obstante lo afirmado por Orren, existen algunas evidencias empíricas que demuestran, en lo que a las políticas sociales y al Estado de bienestar se refiere, que las demandas no son infinitas y que estas van decreciendo conforme se incrementa la intervención gubernamental. Véanse los trabajos compilados por Borre y Scarbrough (1995). 


\section{C) La influencia de otros factores sobre el apoyo político}

Como señalara Miller (1974a y b) las políticas públicas influyen de forma importante sobre el apoyo político pero no son el único factor que lo hace. Además de las políticas se ha de tomar en consideración el entorno económico, social y político-institucional en el que se desenvuelve la acción de gobierno; los intereses, valores y comportamientos de los individuos; y los comportamientos de diversos actores, en particular de los medios de comunicación.

En lo que respecta a las cuestiones económicas habría que distinguir la influencia ejercida por la estructura económica, y en particular la riqueza del país, de aquellas otras relativas a la situación económica en un momento concreto. Esta última es, al menos en parte, fruto de la propia acción gubernamental y suele considerarse como un elemento más -cuando no el único o el más importante- del performance del gobierno y, por tanto, se vincula a las cuestiones arriba apuntadas respecto de los resultados de las políticas públicas. En cuanto a la estructura económica, algunos estudios han mostrado que la cantidad de riqueza producida por una sociedad influye sobre la confianza institucional, de modo que, cuanto más grande sea la riqueza generada menor será el apoyo con el que cuenten sus instituciones democráticas (McAllister 1999). No obstante, señala McAllister que las condiciones económicas y sociales, aunque influyen sobre el apoyo hacia el sistema político, lo hacen en menor medida que otros factores, como la cultura política o las circunstancias históricas, por mencionar sólo algunos.

De acuerdo con el enfoque post-materialista, el descenso de la confianza en el gobierno forma parte de un proceso más amplio de erosión de la deferencia hacia la autoridad que está vinculado, a su vez, a los procesos de modernización y post-modernización ${ }^{16}$. En la fase post-moderna del desarrollo tiene lugar, entre los ciudadanos de las sociedades industriales avanzadas, un declive del respeto a la autoridad y de la confianza en las instituciones jerárquicas, incluidas las autoridades e instituciones gubernamentales. Al mismo tiempo que desciende la confianza en el gobierno se experimenta también un crecimiento del apoyo a la democracia y, especialmente, de los valores democráticos. En las sociedades industriales avanzadas la ciudadanía tiende a rechazar los gobiernos autoritarios y a valorar la democracia en mayor medida que los ciudadanos de las sociedades menos seguras desde un punto de vista económico. Inglehart (1999) resume su tesis en una frase: la post-modernización erosiona el respeto a la autoridad pero incrementa el apoyo a la democracia. Las condiciones de prosperidad y seguridad conducen a un mayor énfasis en la autonomía individual y a la disminución de la deferencia hacia la autoridad. En un entorno de seguridad la deferencia hacia la autoridad tiene altos costes pues se han de subordinar las metas individuales a las colectivas.

Otra cuestión que ha sido objeto de estudio ha sido la de la influencia del capital social ${ }^{17}$ sobre el apoyo político. Para Putnam (1995) la confianza social -la confianza en otra gente- y la confianza política -la confianza en las autoridades-son fenómenos distintos, si bien, desde un punto de vista empírico puede que se relacionen. Sin embargo, las relaciones que vinculan confianza en el gobierno, rendimiento gubernamental y confianza social, compromiso cívico y capital social, son relaciones complejas (Putnam, Pharr y Dalton 2000). No existe un efecto directo de la erosión del capital social sobre la confianza en el gobierno. En este sentido, Newton (1999) ha demostrado que la confianza política no es necesariamente una variación o un producto de la confianza social y que, a nivel individual, no existe una asociación consistente entre confianza política y social, o algo que nos per-

${ }^{16}$ Para esta cuestión véanse los clásicos trabajos de Inglehart especialmente Inglehart (1997a), en el que formula de manera más amplia su teoría, así como otros de sus trabajos más centrados en el tema del apoyo político (1997b y 1999), especialmente este último, en el que aporta una evidencia empírica más extensa a partir del estudio de las tres oleadas de la Encuesta Mundial de Valores.

${ }^{17}$ Con este término se hace referencia a «las características de la organización social, tales como la confianza, las normas y las redes, que pueden mejorar la eficiencia de la sociedad facilitando acciones coordinadas» (Putnam, Leonardi y Nanetti 1993). 
mita deducir que el capital social se transforme necesariamente en capital político. Sin embargo, lo que si existe es un efecto indirecto. En la medida en que la confianza social influye sobre el rendimiento gubernamental y el rendimiento incide a su vez sobre la confianza en el gobierno se acaba produciendo un efecto indirecto de la confianza social sobre la política (Putnam, Pharr y Dalton 2000) ${ }^{18}$.

En cuanto al entorno político-institucional la relación de factores a considerar es muy extensa ${ }^{19}$. Así, se dispone de investigaciones que han analizado la relación entre apoyo político y la edad de la democracia (Fuchs, Guidorossi, y Svensson 1995; McAllister 1999), el nivel de democratización (Norris 1999), el tipo de democracia, mayoritaria o de consenso (Anderson y Guillory 1997), las formas de Estado y las formas de gobierno (Norris 1999), el diseño del sistema electoral (Norris 1999), las características del sistema de partidos en cuanto a su grado de fragmentación y polarización (Weil 1989; Miller y Listhaug 1990 y Norris 1999), el tipo de coalición gubernamental que se forme (Weil 1989), la estabilidad de los ejecutivos (Harmel y Robertson 1986; Weil 1989), la propia celebración de elecciones y si en estas tiene lugar o no alternancia en el poder (Clarke, Dutt y Kornberg 1993). Por otra parte, las investigaciones sobre la popularidad de los presidentes han identificado diversos factores que puedan afectar a las percepciones de los ciudadanos respecto de los líderes de los ejecutivos ${ }^{20}$, incluyendo cuestiones como: el tiempo transcurrido desde la elección del presidente; hechos singulares, como crisis de muy diversa naturaleza y, en particular, las crisis internacionales y las guerras (Clarke, Dutt y Kornberg 1993); y determinadas condiciones políticas previas, como por ejemplo, la valoración con la que contaba un líder político antes de su elección.

En lo relativo a los intereses, valores y comportamientos de los ciudadanos la relación de variables que puedan afectar al apoyo político es todavía más extensa que la de los factores de carácter político-institucional. Así, en lo que respecta a las variables socio-demográficas más frecuentemente indagadas por los estudios de apoyo político, está la edad, que mantiene una relación directa con el apoyo a diversos objetos políticos, especialmente con la satisfacción con el funcionamiento de la democracia y las instituciones y autoridades del régimen. Esto tiene que ver con los cambios culturales y la revolución silenciosa de la que hablaba Inglehart (1971) y el desplazamiento generacional a través de las diversas cohortes de edad. Otra variable que se relaciona con el apoyo, en este caso en sentido inverso en lo que respecta a las instituciones y autoridades en ejercicio, es el nivel de instrucción, por lo que supone de incremento de la capacidad cognitiva de los ciudadanos (Dalton 1996) y de establecimiento de parámetros más exigentes en cuanto a los resultados y procedimientos a través de los cuales se juzga la acción gubernamental.

Los valores también inciden sobre el apoyo. Se ha observado como la religiosidad, que se asocia a la deferencia hacia la autoridad y las instituciones jerárquicas, está relacionada de forma directa con el apoyo a las instituciones (Listhaug y Wiberg 1995). La ubicación de un individuo en el eje materialismo-postmaterialismo es también, como se ha mencionado más arriba, otros de los factores que inciden sobre el apoyo. Finalmente, la posición en el eje izquierda-derecha es una variable asociada a las preferencias de política pública y la correspondiente satisfacción o insatisfacción con las políticas desarrolladas por los gobiernos ${ }^{21}$.

${ }^{18}$ Así parece confirmarlo el trabajo de Newton y Norris (2000) que encontraron, tomando como unidad de análisis los datos agregados a nivel nacional de las 17 democracias de la Trilateral -a partir de la Encuesta Mundial de Valores de principios de las décadas de 1980 y 1990-, coeficientes de asociación significativos entre confianza en las instituciones políticas -policía, administración de justicia, parlamento y administración pública-y confianza social -no así con la pertenencia a entidades cívicas-. do la cuestión.

${ }^{19}$ Nos limitamos aquí a mencionarlos indicando para cada uno de ellos algunas referencias bibliográficas en las que se haya aborda-

${ }^{20}$ Para una revisión de la literatura al respecto véase Gronke y Newman (2000).

${ }^{21}$ Miller (1974a) hablaba de dos tipos de cinismo político que pueden surgir ante políticas centristas, uno de izquierdas partidario del cambio social y otro de derechas que propugna el control social. 
Putnam, Pharr y Dalton (2000) mencionan entre los factores que influyen sobre la confianza política el de la disponibilidad de información respecto al performance democrático. Desde esta perspectiva, el papel de los medios de comunicación es particularmente relevante. En su revisión sobre el estado de la cuestión relativa a este asunto Norris (2000) distingue entre dos tipos de teorías: la del videomalestar y la de la movilización. De acuerdo con la primera, la forma en que se transmiten las noticias políticas contribuiría a un incremento del cinismo político. En este sentido, los medios abordan las noticias políticas como una especie de carrera de caballos en la que se trata de ver quién va por delante y quién por detrás; se destacan los aspectos conflictivos y negativos; cada medio y los actores políticos siguen sus propias estrategias por enmarcar las noticias de modo que les resulten favorables; y se subrayan los elementos más sensacionalistas, superficiales y populistas con objeto de mantener la audiencia.

La teoría de la movilización, por su parte, dibujaría un panorama distinto según el cual los medios favorecerían la participación y otros comportamientos cívicos. Las noticias en los medios contribuirían a movilizar y reforzar a los electores, así como a ilustrarlos sobre las diversas opciones políticas, para que puedan realizar de una forma más racional sus decisiones electorales y la formación de sus preferencias. Se destaca que en las sociedades modernas los ciudadanos disponen de un amplio abanico de medios de comunicación, desde la prensa hasta Internet, lo que ha disminuido los costes de obtención de información para un público con niveles de instrucción cada vez más altos y con las habilidades necesarias para procesar ésa información. El resultado sería un electorado mejor preparado para participar políticamente, sofisticado y crítico respecto a las autoridades.

\section{Metodología}

Desde el punto de vista metodológico la investigación consiste en lo siguiente:

- Se ha tomado como unidad de análisis a los individuos, analizando sus actitudes hacia diversos objetos políticos y políticas públicas.

- Se han seleccionado una serie de preguntas de las encuestas del CIS arriba mencionadas, a partir de las cuales se intenta evaluar el grado de apoyo con el que cuentan los objetos políticos analizados: la identidad con la comunidad autónoma, la preferencia por la forma de la organización territorial del Estado, la satisfacción con el funcionamiento del Estado de las autonomías, la valoración de la labor del parlamento y del gobierno autonómico y, por último, la valoración de la gestión del presidente autonómico en ejercicio.

- A partir de la repuesta a dos preguntas más, procedentes de las mismas encuestas del CIS, se han construido dos escalas múltiples: una sobre valoración de las políticas del gobierno autonómico y otra sobre la valoración de los procedimientos.

- Se han empleado varios modelos de regresión, uno para cada objeto político, con los que se intenta estimar el grado de apoyo expresado a cada objeto a partir de la valoración de las políticas y los procedimientos.

- Los resultados obtenidos al aplicar dichos modelos de regresión nos han permitido responder a diferentes preguntas de investigación, que luego se detallarán.

- Finalmente, se han aplicado diversos mecanismos de control, con la intención de observar en qué medida los resultados iniciales se mantienen, o no, en presencia de los controles efectuados.

En cuanto a las preguntas elegidas de las encuestas del CIS, su texto se ha trascrito en la tabla 1. Se recogen también en esta tabla las transformaciones que se han realizado, tanto para estimar el grado de apoyo político, como la valoración de las políticas y los procedimientos. 


\section{TABLA 1 \\ Textos de las preguntas y transformaciones efectuadas}

\begin{tabular}{|c|c|c|}
\hline Variable & Texto de la pregunta & Transformación \\
\hline $\begin{array}{l}\text { Identidad con la Comunidad } \\
\text { Autónoma }\end{array}$ & $\begin{array}{l}\text { ¿Con cuál de las siguientes frases se identi- } \\
\text { fica Ud. en mayor medida? } \\
\text { Me siento únicamente español } \\
\text { Me siento más español que andaluz } \\
\text { Me siento tan español como andaluz } \\
\text { Me siento más andaluz que español } \\
\text { Me siento únicamente andaluz }\end{array}$ & $\begin{array}{l}\text { Identidad baja: me siento únicamente espa- } \\
\text { ñol } \\
\text { Identidad media: me siento más español } \\
\text { que andaluz } \\
\text { Identidad alta: me siento tan español como } \\
\text { andaluz + me siento más andaluz que espa- } \\
\text { ñol + me siento únicamente andaluz }\end{array}$ \\
\hline $\begin{array}{l}\text { Preferencias de organización del } \\
\text { Estado. }\end{array}$ & $\begin{array}{l}\text { Le voy a presentar ahora algunas fórmulas } \\
\text { alternativas de organización del Estado en } \\
\text { España. Dígame, por favor, ¿con cuál está } \\
\text { Ud. más de acuerdo? } \\
\text { Un Estado con un único Gobierno Central } \\
\text { sin autonomías } \\
\text { Un Estado con Comunidades Autónomas } \\
\text { como en la actualidad. } \\
\text { Un Estado en el que las Comunidades } \\
\text { Autónomas tengan mayor autonomía que } \\
\text { en la actualidad. } \\
\text { Un Estado en que se reconociese a las } \\
\text { autonomías la posibilidad de convertirse en } \\
\text { naciones independientes. }\end{array}$ & $\begin{array}{l}\text { Apoyo bajo = Un Estado con un único } \\
\text { Gobierno Central sin autonomías + un } \\
\text { Estado en que se reconociese a las autono- } \\
\text { mías la posibilidad de convertirse en nacio- } \\
\text { nes independientes. } \\
\text { Apoyo medio = Un Estado en el que las } \\
\text { Comunidades Autónomas tengan mayor } \\
\text { autonomía que en la actualidad. } \\
\text { Apoyo alto = Un Estado con Comunidades } \\
\text { Autónomas como en la actualidad. }\end{array}$ \\
\hline $\begin{array}{l}\text { Satisfacción con el funcionamiento } \\
\text { del Estado de las autonomías }\end{array}$ & $\begin{array}{l}\text { Y, en conjunto, ¿cómo diría Ud. que ha } \\
\text { funcionado durante estos años la organiza- } \\
\text { ción del Estado en Comunidades } \\
\text { Autónomas...? Muy bien, bien, regular, mal, } \\
\text { muy mal. }\end{array}$ & $\begin{array}{l}\text { No se ha transformado la variable excepto } \\
\text { para ordenarla de menor a mayor apoyo, es } \\
\text { decir, de muy mal a muy bien. }\end{array}$ \\
\hline $\begin{array}{l}\text { Valoración de la labor del parla- } \\
\text { mento autonómico }\end{array}$ & $\begin{array}{l}\text { A continuación, quisiera que me dijera } \\
\text { cómo calificaría Ud. la labor que desempe- } \\
\text { ña cada una de las siguientes instituciones: } \\
\text { muy buena, buena, regular, mala o muy } \\
\text { mala... su Parlamento autonómico. }\end{array}$ & $\begin{array}{l}\text { No se ha transformado la variable excepto } \\
\text { para ordenarla de menor a mayor apoyo, es } \\
\text { decir, de muy mala a muy buena. }\end{array}$ \\
\hline $\begin{array}{l}\text { Valoración de la labor del gobierno } \\
\text { autonómico }\end{array}$ & $\begin{array}{l}\text { A continuación, quisiera que me dijera } \\
\text { cómo calificaría Ud. la labor que desempe- } \\
\text { ña cada una de las siguientes instituciones: } \\
\text { muy buena, buena, regular, mala o muy } \\
\text { mala... su Gobierno autonómico. }\end{array}$ & $\begin{array}{l}\text { No se ha transformado la variable excepto } \\
\text { para ordenarla de menor a mayor apoyo, es } \\
\text { decir, de muy mala a muy buena. }\end{array}$ \\
\hline $\begin{array}{l}\text { Valoración de la gestión del presi- } \\
\text { dente autonómico en ejercicio }\end{array}$ & $\begin{array}{l}\text { En conjunto, ¿cómo calificaría Ud. la ges- } \\
\text { tión realizada por el Presidente, Manuel } \\
\text { Chaves, al frente de la Junta de Andalucía } \\
\text { durante los últimos dos o tres años...? Muy } \\
\text { buena, buena, regular, mala, muy mala. }\end{array}$ & $\begin{array}{l}\text { No se ha transformado la variable excepto } \\
\text { para ordenarla de menor a mayor apoyo, es } \\
\text { decir, de muy mala a muy buena. }\end{array}$ \\
\hline
\end{tabular}




\begin{tabular}{|c|c|c|}
\hline Variable & Texto de la pregunta & Transformación \\
\hline $\begin{array}{l}\text { Valoración de las políticas del } \\
\text { gobierno autonómico }\end{array}$ & $\begin{array}{l}\text { Voy a leerle ahora una serie de cuestiones } \\
\text { de interés general y me gustaría que Ud. me } \\
\text { dijera si considera muy buena, buena, regu- } \\
\text { lar, mala o muy mala la política que el } \\
\text { Gobierno de su Comunidad Autónoma ha } \\
\text { seguido en relación con cada una de ellas. } \\
\text { La vivienda. } \\
\text { La seguridad ciudadana. } \\
\text { La educación. } \\
\text { La lucha contra la droga. } \\
\text { El desempleo. } \\
\text { Las infraestructuras: carreteras, obras públi- } \\
\text { cas, etc. } \\
\text { La situación de la agricultura y la pesca. } \\
\text { La sanidad. } \\
\text { La protección del medio ambiente. } \\
\text { El funcionamiento del transporte público. } \\
\text { La situación de la industria y el comercio. } \\
\text { El funcionamiento de la Administración } \\
\text { autonómica. }\end{array}$ & $\begin{array}{l}\text { Se ha construido una escala múltiple a partir } \\
\text { de las respuestas a esta pregunta para aque- } \\
\text { llos entrevistados que han respondido entre } \\
7 \text { y } 12 \text { íems. } \\
\text { La forma de cálculo ha consistido en la } \\
\text { suma de los valores de las respuestas clasifi- } \\
\text { cados entre muy buena }=5 \text { y muy mala }=1 \\
\text { dividiendo el resultado por el número de } \\
\text { items a los que el entrevistado ha respondi- } \\
\text { do.Fiabilidad de la escala. Alfa de Cronbach: } \\
1998=0,879 ; 2002=0,871\end{array}$ \\
\hline Valoración procedimientos & $\begin{array}{l}\text { Ahora me gustaría que Ud. me dijera si, a } \\
\text { su juicio, el actual Gobierno de su } \\
\text { Comunidad Autónoma ha demostrado... } \\
\text { Capacidad para defender los intereses de la } \\
\text { Comunidad Autónoma. } \\
\text { Honradez. } \\
\text { Capacidad de diálogo. } \\
\text { Eficacia. } \\
\text { Capacidad de comunicarse con el hombre } \\
\text { de la calle. } \\
\text { Conocimiento de los problemas de la } \\
\text { Comunidad Autónoma. }\end{array}$ & $\begin{array}{l}\text { Se ha construido una escala múltiple a partir } \\
\text { de las respuestas a esta pregunta para aque- } \\
\text { llos entrevistados que han respondido entre } \\
4 \text { y } 6 \text { ítems.La forma de cálculo ha consisti- } \\
\text { do en la suma de los valores de las respues- } \\
\text { tas clasificados entre si }=2 \text { y no }=1 \text { divi- } \\
\text { diendo el resultado por el número de ítems } \\
\text { a los que el entrevistado ha } \\
\text { respondido.Fiabilidad de la escala. Alfa de } \\
\text { Cronbach: } 1998=0,889 ; 2002=0,885\end{array}$ \\
\hline $\begin{array}{l}\text { Valoración de la situación econó- } \\
\text { mica actual de la comunidad } \\
\text { autónoma }\end{array}$ & $\begin{array}{l}\text { Y refiriéndonos ahora a la situación econó- } \\
\text { mica actual de la Comunidad Autónoma de } \\
\text { Andalucía, ¿cómo la calificaría Ud...? Muy } \\
\text { buena, buena, regular, mala, muy mala. }\end{array}$ & $\begin{array}{l}\text { No se ha transformado la variable excepto } \\
\text { para ordenarla de muy mala a muy buena. }\end{array}$ \\
\hline $\begin{array}{l}\text { Valoración retrospectiva de la } \\
\text { situación económica de la } \\
\text { comunidad autónoma }\end{array}$ & $\begin{array}{l}\text { Y, ¿cree Ud. que la situación económica de } \\
\text { la Comunidad Autónoma de Andalucía es } \\
\text { ahora mucho mejor, mejor, peor o mucho } \\
\text { peor que hace tres años? }\end{array}$ & $\begin{array}{l}\text { No se ha transformado la variable excepto } \\
\text { para ordenarla de mucho peor a mucho } \\
\text { mejor }\end{array}$ \\
\hline
\end{tabular}




\begin{tabular}{|c|c|c|}
\hline Variable & Texto de la pregunta & Transformación \\
\hline $\begin{array}{l}\text { Valoración retrospectiva de las } \\
\text { políticas del gobierno autonómico }\end{array}$ & $\begin{array}{l}\text { De esta misma serie de cuestiones o pro- } \\
\text { blemas, quisiera que me dijera, para cada } \\
\text { una de ellas, si cree Ud. que en los últimos } \\
\text { tres años han mejorado o han empeorado } \\
\text { en la Comunidad Autónoma de Andalucía. } \\
\text { La vivienda. } \\
\text { La seguridad ciudadana. } \\
\text { La educación. } \\
\text { La lucha contra la droga. } \\
\text { El desempleo. } \\
\text { Las infraestructuras: carreteras, obras públi- } \\
\text { cas, etc. } \\
\text { La situación de la agricultura y la pesca. } \\
\text { La sanidad. } \\
\text { La protección del medio ambiente. } \\
\text { El funcionamiento del transporte público. } \\
\text { La situación de la industria y el comercio. } \\
\text { El funcionamiento de la Administración } \\
\text { autonómica. }\end{array}$ & $\begin{array}{l}\text { Se ha construido una escala múltiple a partir } \\
\text { de las respuestas a esta pregunta para aque- } \\
\text { llos entrevistados que han respondido entre } \\
7 \text { y } 12 \text { items. } \\
\text { La forma de cálculo ha consistido en la } \\
\text { suma de los valores de las respuestas clasifi- } \\
\text { cados entre ha mejorado }=3 \text {, sigue igual = } \\
2 \text { y ha empeorado = } 1 \text { dividiendo el resulta- } \\
\text { do por el número de ítems a los que el } \\
\text { entrevistado ha respondido. } \\
\text { Fiabilidad de la escala. Alfa de Cronbach: } \\
1998=0.885 ; 2002=0.876 \text {. }\end{array}$ \\
\hline $\begin{array}{l}\text { Proximidad al partido del presiden- } \\
\text { te de la Comunidad Autónoma }\end{array}$ & $\begin{array}{l}\text { Voy a citarle ahora una serie de partidos } \\
\text { políticos. Dígame, por favor, si se encuen- } \\
\text { tra Ud. Muy cercano, cercano, ni cercano ni } \\
\text { distante, distante o muy distante de cada } \\
\text { uno de ellos. }\end{array}$ & $\begin{array}{l}\text { Transformación de la variable en un indica- } \\
\text { dor de proximidad al partido político por el } \\
\text { que resultó elegido el presidente de la } \\
\text { comunidad autónoma. Variable ordinal que } \\
\text { va desde muy distante hasta muy cercano. }\end{array}$ \\
\hline Voto al partido ganador & $\begin{array}{l}\text { ¿Me podría decir a qué partido o coalición } \\
\text { votó Ud. en las elecciones autonómicas de } \\
\text {...? }\end{array}$ & $\begin{array}{l}\text { Transformación de la variable en un indica- } \\
\text { dor de voto al partido por el que resultó } \\
\text { elegido el presidente de la comunidad autó- } \\
\text { noma. } 0 \text { = no votó al partido del presidente; } \\
1 \text { = votó al partido del presidente. }\end{array}$ \\
\hline
\end{tabular}

Las transformaciones efectuadas sobre algunas respuestas -concretamente las de identidad con la comunidad autónoma y las preferencias de organización territorial- van dirigidas a estimar diversos grados de apoyo a la comunidad política y a los principios del régimen respectivamente. El resto de las transformaciones se han realizado con la única finalidad de adaptarlas a un orden natural que facilite la lectura de los datos (véase la tabla 1).

Respecto a las variables independientes se ha de señalar lo siguiente: se ha optado por analizar los resultados de las políticas a partir de una escala múltiple en la que se contemplan, simultáneamente, un amplio abanico de políticas públicas. La valoración de la situación económica, que suele considerarse como el indicador de performance gubernamental por antonomasia, ha sido utilizada en este estudio como variable de control. Como se verá más adelante, aunque esta variable ejerce una cierta influencia sobre el apoyo político, su peso relativo, al menos en lo que respecta al nivel autonómico, es sensiblemente inferior al que cabe deducir de la consideración de un amplio conjunto de políticas ${ }^{22}$.

${ }^{22}$ Ello puede deberse, en parte, a la elección de un nivel intermedio de gobierno, al que normalmente se le atribuye un papel de menor relevancia que al gobierno central en cuanto al buen funcionamiento de la economía. Por otro lado, el año 2002 se sitúa en un ciclo de crecimiento económico y del empleo, lo que puede hacer que la importancia otorgada a la política económica, que no tiene por qué ser constante a lo largo del tiempo, pase a un lugar menos relevante. 
La escala de valoración de procedimientos que hemos elaborado puede generar algunas dudas en el lector. Para intentar despejarlas quisiéramos señalar que, aunque los aspectos considerados en la misma son de muy diversa naturaleza - desde la eficacia a la honestidad, pasando por otras cuestiones-, todos ellos conforman un único factor ${ }^{23}$. En una investigación previa en la que se diseñaron instrumentos muy detallados considerando catorce dimensiones con objeto de evaluar las percepciones de los ciudadanos respecto de los aspectos procedimentales de las administraciones públicas, todas esas dimensiones se agrupaban también en un único factor ${ }^{24}$. A mayor abundamiento, si analizamos a lo largo del tiempo los distintos indicadores de gobernabilidad empleados por el Banco Mundial, de nuevo todos se resumen en un factor único. ¿Se trata de una casualidad estadística? Desde nuestro punto de vista no es así, puesto que ya recurramos a las opiniones de los ciudadanos o a las de los expertos, a datos individuales o agregados, a indicadores de opinión o a indicadores «objetivos», a escalas muy simples o a las más complejas, a análisis locales o a comparaciones internacionales, en unas fechas o en otras, el resultado es siempre el mismo. La conclusión a la que llegamos es que la cuestión de cómo se gobierna es un asunto en el que, aunque puedan distinguirse muy diferentes dimensiones, todas ellas constituyen un único factor, puesto que una valoración en uno de sus componentes suele ir acompañada de valoraciones similares en otros componentes. En otras palabras, las distintas dimensiones de procedimiento están fuertemente asociadas entre sí. De este modo, parece difícil que una organización pueda ser eficiente y corrupta al mismo tiempo.

Los modelos de regresión diseñados se recogen en la tabla 2. Los seis primeros incluyen únicamente nuestras dos variables independientes, mientras que los seis siguientes incorporan también las variables de control. Estos últimos han sido elaborados con la finalidad de comprobar si las asociaciones que hemos observado entre los resultados y los procedimientos de las políticas y el apoyo a los distintos objetos se mantienen, o no, en presencia de otras variables que, conforme a la literatura existente, sabemos que pueden influir sobre el apoyo político.

Estos modelos nos han de permitir responder a diversas preguntas sobre las que, a su vez, organizaremos la exposición de los resultados de la investigación: ¿en qué medida podemos interpretar las variaciones en el apoyo político a partir de las percepciones que tienen los ciudadanos sobre las políticas públicas? ¿Sobre qué tipo de objetos políticos influyen más las políticas? ¿Qué nos permite explicar mejor la variación en el apoyo político, las políticas públicas o los otros factores que se han utilizado como variables de control? ¿Qué efecto ejerce sobre el apoyo político cada una de las variables independientes tomadas en consideración de forma separada? ¿Cuál es el peso relativo de cada variable independiente? O lo que es lo mismo ¿Qué influye más sobre el apoyo político, la valoración de los procedimientos o la de los resultados?

${ }^{23}$ Tras aplicar la técnica del análisis factorial mediante el método de componentes principales a las respuestas ofrecidas por los entrevistados a estas seis preguntas se obtuvo un único factor. Así, los componentes obtenidos fueron los siguientes: capacidad de comunicarse con el hombre de la calle (0,783); capacidad de diálogo (0,800); capacidad para defender los intereses de la Comunidad Autónoma (0,815); conocimiento de los problemas de la Comunidad Autónoma (0,765); eficacia $(0,810)$; honradez (0,804). El eigenvalue fue 3.8. El \% de varianza explicada por el factor fue de 63.4.

${ }^{24}$ Se trata de un estudio realizado a una muestra representativa de 1.000 personas de 18 o más años de la Comunidad de Madrid en el año 2000 en el que se pedía a los entrevistados que indicaran qué administración pública -todas, la central, la autonómica, la municipal o ninguna-se ajustaba mejor a las siguiente frases: respeta los derechos y libertades de los ciudadanos; cumple y hace cumplir las leyes; persigue el interés general de todos los ciudadanos; trata por igual a todos los ciudadanos; fomenta la participación de los ciudadanos; actúa de forma responsable; es sensible y receptiva a lo que quieren y necesitan los ciudadanos; rinde cuentas a los ciudadanos de lo que hace; se ocupa del bienestar de todos facilitando el acceso a servicios y prestaciones sociales; se preocupa más por los más desfavorecidos; intenta reducir las diferencias entre las personas con ingresos altos e ingresos bajos; presta servicios de calidad; es eficaz a la hora de resolver los problemas y prestar servicios; hace un uso eficiente del dinero público. A partir de esta información se realizó un análisis factorial mediante el método de componentes principales que arrojó como resultado un único factor que permitía interpretar el 63.6 por 100 de la varianza de todas las preguntas analizadas.

${ }^{25}$ El Banco Mundial viene calculando cada dos años una serie de indicadores de gobernabilidad. Con este término hacen referencia a las tradiciones e instituciones a través de las cuales se ejerce la autoridad. Calculan seis indicadores a los que denominan: imperio de la ley, eficacia del gobierno, control de la corrupción, estabilidad política, calidad de las regulaciones y voz y rendición de cuentas. Véase para más detalles Kaufman, Kraay y Mastruzzi (2005). Pues bien, si aplicamos el análisis factorial a estos indicadores volvemos a obtener un único factor que permite explicar el 84.4 por 100 de la varianza de los seis indicadores en 1996, el 87.8 en 1998, el 84.4 en 2000, el 87.8 en 2002 y el 87.0 en 2004. 
En cuanto a los mecanismos de control se ha recurrido -además de a los modelos de regresión que incluyen las variables de control- a realizar los cálculos para cada una de las diecisiete comunidades autónomas, por separado.

\section{TABLA 2}

Modelos de regresión apoyo político y políticas públicas

Modelo 1. Identidad con la Comunidad Autónoma y politicas públicas. $\mathrm{ICA}=a+b \mathrm{VPOL}+c \mathrm{VPRO}+e$

Modelo 2. Preferencias de organización del Estado y políticas públicas. $\mathrm{PFE}=a+b \mathrm{VPOL}+c \mathrm{VPRO}+e$

Modelo 3. Satisfacción con el funcionamiento del Estado de las autonomías y politicas puiblicas $\mathrm{SFE}=a+b \mathrm{VPOL}+c \mathrm{VPRO}+e$

Modelo 4. Apoyo al parlamento autonómico y políticas públicas.

$$
\mathrm{VPA}=a+b \mathrm{VPOL}+c \mathrm{VPRO}+e
$$

Modelo 5. Apoyo al gobierno autonómico y politicas públicas.

$$
\mathrm{VGA}=a+b \mathrm{VPOL}+c \mathrm{VPRO}+e
$$

Modelo 6. Apoyo al presidente autonómico en ejercicio y politicas públicas.

$$
\mathrm{VPA}=a+b \mathrm{VPOL}+c \mathrm{VPRO}+e
$$

Modelo 7. Identidad con la Comunidad Autónoma, variables de control y politicas públicas.

$\mathrm{ICA}=a+b \mathrm{VPOL}+c \mathrm{VPRO}+d \mathrm{VECO}+f \mathrm{VRECO}+g \mathrm{VRPOL}+b \mathrm{SEXO}+i \mathrm{EDAD}+j \mathrm{EDU}+k$ $\mathrm{RELIG}+l \mathrm{PROX}+m \mathrm{VGAN}+n \mathrm{PIB}+o \mathrm{ASOC}+p \mathrm{NEP}+q \mathrm{IPS}+r \mathrm{COAL}+s \mathrm{CPRE}+t \mathrm{NAP}+e$

Modelo 8. Preferencias de organización del Estado, variables de control y politicas públicas.

$\mathrm{PFE}=a+b \mathrm{VPOL}+c \mathrm{VPRO}+d \mathrm{VECO}+f \mathrm{VRECO}+g \mathrm{VRPOL}+b \mathrm{SEXO}+i \mathrm{EDAD}+j \mathrm{EDU}+k$ $\mathrm{RELIG}+l \mathrm{PROX}+m \mathrm{VGAN}+n \mathrm{PIB}+o \mathrm{ASOC}+p \mathrm{NEP}+q \mathrm{IPS}+r \mathrm{COAL}+s \mathrm{CPRE}+t \mathrm{NAP}+e$

Modelo 9. Satisfacción con el funcionamiento del Estado de las autonomias, variables de control y politicas públicas. $\mathrm{SFE}=a+b \mathrm{VPOL}+c \mathrm{VPRO}+d \mathrm{VECO}+f \mathrm{VRECO}+g \mathrm{VRPOL}+b \mathrm{SEXO}+i \mathrm{EDAD}+j \mathrm{EDU}+k$ $\mathrm{RELIG}+l \mathrm{PROX}+m \mathrm{VGAN}+n \mathrm{PIB}+o \mathrm{ASOC}+p \mathrm{NEP}+q \mathrm{IPS}+r \mathrm{COAL}+s \mathrm{CPRE}+t \mathrm{NAP}+e$

Modelo 10. Apoyo al parlamento autonómico, variables de control y políticas públicas.

$\mathrm{VPA}=a+b \mathrm{VPOL}+c \mathrm{VPRO}+d \mathrm{VECO}+f \mathrm{VRECO}+g \mathrm{VRPOL}+b \mathrm{SEXO}+i \mathrm{EDAD}+j \mathrm{EDU}+k$ $\mathrm{RELIG}+l \mathrm{PROX}+m \mathrm{VGAN}+n \mathrm{PIB}+o \mathrm{ASOC}+p \mathrm{NEP}+q \mathrm{IPS}+r \mathrm{COAL}+s \mathrm{CPRE}+t \mathrm{NAP}+e$

Modelo 11. Apoyo al gobierno autonómico, variables de control y politicas públicas. $\mathrm{VGA}=a+b \mathrm{VPOL}+c \mathrm{VPRO}+d \mathrm{VECO}+f \mathrm{VRECO}+g \mathrm{VRPOL}+b \mathrm{SEXO}+i \mathrm{EDAD}+j \mathrm{EDU}+k$ $\mathrm{RELIG}+l \mathrm{PROX}+m \mathrm{VGAN}+n \mathrm{PIB}+o \mathrm{ASOC}+p \mathrm{NEP}+q \mathrm{IPS}+r \mathrm{COAL}+s \mathrm{CPRE}+t \mathrm{NAP}+e$

Modelo 12. Apoyo al presidente autonómico en ejercicio, variables de control y politicas públicas.

$\mathrm{VPA}=a+b \mathrm{VPOL}+c \mathrm{VPRO}+d \mathrm{VECO}+f \mathrm{VRECO}+g \mathrm{VRPOL}+b \mathrm{SEXO}+i \mathrm{EDAD}+j \mathrm{EDU}+k$ $\mathrm{RELIG}+l \mathrm{PROX}+m \mathrm{VGAN}+n \mathrm{PIB}+o \mathrm{ASOC}+p \mathrm{NEP}+q \mathrm{IPS}+r \mathrm{COAL}+s \mathrm{CPRE}+t \mathrm{NAP}+e$ 
$\mathrm{ICA}=\quad$ Identidad con la Comunidad Autónoma

$\mathrm{PFE}=$ Preferencias de organización del Estado.

$\mathrm{SFE}=$ Satisfacción con el funcionamiento del Estado de las autonomías.

$\mathrm{VPA}=$ Valoración del parlamento autonómico.

VGA $=$ Valoración del gobierno autonómico.

$\mathrm{VPA}=\quad$ Valoración del presidente autonómico.

VPOL = Valoración de las políticas del gobierno autonómico.

VPRO $=$ Valoración de los procedimientos.

VECO $=$ Valoración de la situación económica actual de la Comunidad Autónoma.

VRECO = Valoración retrospectiva de la situación económica de la Comunidad Autónoma.

VRPOL = Valoración retrospectiva de las políticas de la Comunidad Autónoma

SEXO $=$ Sexo.

$\mathrm{EDAD}=$ Edad

$\mathrm{EDU}=$ Nivel educativo.

RELIG = Religiosidad

PROX $=$ Proximidad al partido del presidente de la Comunidad Autónoma.

VGAN = Voto al partido ganador

PIB = PIB per capita de la Comunidad Autónoma.

ASOC $=\%$ de personas de 18 o más años que pertenecen a asociaciones voluntarias

(a ambas muestras se aplican datos de 1998).

NEP $=$ Número efectivo de partidos

IPS $=\quad$ Índice de Polarización de Sartori

COAL $=$ Coalición sobredimensionada, monocolor o coalición sin mayoría absoluta $=0 /$

Coalición ganadora mínima, monocolor mayoría absoluta $=1$

$\mathrm{CPRE}=$ Cese del presidente de la Comunidad entre elecciones

$\mathrm{NAP}=\quad$ Número de años desde la elección del presidente de la Comunidad.

$a, b, c, d, f, g, b, j, k, l, m, n, 0, p, q, r, s, t=$ parámetros a calcular.

$e=$ error.

\section{Resultados}

\section{A) ¿En qué medida podemos interpretar las variaciones en el apoyo político a partir de las percepcio- nes que tienen los ciudadanos sobre las políticas públicas?}

La respuesta ofrecida a esta pregunta depende del tipo de objeto político que consideremos. En el caso de la identidad con la comunidad autónoma el efecto combinado que ejercen la valoración de las políticas y los procedimientos es nulo, pues para el año 2002 ambas variables únicamente permiten explicar el 0.5 por 100 de la varianza 
-véase la tabla 3-26. En el otro extremo tenemos el caso del gobierno autonómico del que se puede interpretar el 47.6 por 100 de la varianza en el apoyo expresado, a partir de las percepciones sobre las políticas públicas.

Por otra parte, cuando se comparan los diversos objetos políticos entre sí, la pauta que se observa se ajusta bien a las previsiones de la teoría. Así, la influencia ejercida por las políticas es nula en lo que respecta a la comunidad política y los principios del régimen -en nuestro caso la identidad con la comunidad autónoma y las preferencias de organización territorial del Estado- y muy elevada en el caso de las instituciones del régimen y los actores políticos -el parlamento, el gobierno y el presidente autonómico en ejercicio-. La satisfacción con el funcionamiento del Estado de las autonomías, un indicador de rendimiento del régimen, se encuentra en una posición intermedia entre ambos extremos. Es decir, se trata de resultados consistentes con el planteamiento de Easton, sintetizado al principio de este trabajo, y la diferente capacidad que este autor atribuye a los outputs del sistema político para influir sobre los diversos objetos políticos y el tipo de apoyo, difuso o específico, del que se trate.

\section{TABLA 3}

\section{Valoración de las politicas, valoración de los procedimientos y apoyo politico}

\begin{tabular}{|c|c|c|c|c|c|c|c|}
\hline & & $\begin{array}{l}\text { Identidad } \\
\text { con la } \\
\text { Comunidad } \\
\text { Autónoma }\end{array}$ & $\begin{array}{l}\text { Preferencias } \\
\text { de } \\
\text { organización } \\
\text { del Estado }\end{array}$ & $\begin{array}{l}\text { Satisfacción con } \\
\text { el funcionamiento } \\
\text { del Estado } \\
\text { de las autonomías }\end{array}$ & $\begin{array}{l}\text { Valoración } \\
\text { de la labor } \\
\text { del Parlamento } \\
\text { autonómico }\end{array}$ & $\begin{array}{c}\text { Valoración } \\
\text { de la labor } \\
\text { del Gobierno } \\
\text { autonómico }\end{array}$ & $\begin{array}{l}\text { Valoración } \\
\text { de la gestión } \\
\text { del Presidente } \\
\text { autonómico } \\
\text { en ejercicio }\end{array}$ \\
\hline (Constante) & $\begin{array}{l}B \\
t\end{array}$ & $\begin{array}{r}2,344 \\
50,6\end{array}$ & $\begin{array}{r}1,787 \\
36,2\end{array}$ & $\begin{array}{r}1,876 \\
44,2\end{array}$ & $\begin{array}{r}0,775 \\
20,3\end{array}$ & $\begin{array}{r}0,364 \\
10,2\end{array}$ & $\begin{array}{r}0,234 \\
5,4\end{array}$ \\
\hline $\begin{array}{l}\text { Valoración } \\
\text { políticas }\end{array}$ & $\begin{array}{l}B \\
\beta \\
t\end{array}$ & $\begin{array}{r}0,080 * * \\
0,061 \\
4,6\end{array}$ & $\begin{array}{r}0,139 * * \\
0,100 \\
7,5\end{array}$ & $\begin{array}{r}0,305^{* *} \\
0,236 \\
19,1\end{array}$ & $\begin{array}{r}0,426 * * \\
0,330 \\
29,3\end{array}$ & $\begin{array}{r}0,467 * * \\
0,336 \\
34,4\end{array}$ & $\begin{array}{r}0,362 * * \\
0,223 \\
22,2\end{array}$ \\
\hline \multirow[t]{2}{*}{$\begin{array}{l}\text { Valoración } \\
\text { procedimientos }\end{array}$} & $\begin{array}{l}B \\
\beta \\
t\end{array}$ & $\begin{array}{r}0,026 \\
0,014 \\
1,0\end{array}$ & $\begin{array}{r}0,083 * * \\
0,041 \\
3,1\end{array}$ & $\begin{array}{r}0,381 * * \\
0,202 \\
16,3\end{array}$ & $\begin{array}{r}0,732 * * \\
0,388 \\
34,4\end{array}$ & $\begin{array}{r}0,911 * * \\
0,448 \\
45,9\end{array}$ & $\begin{array}{r}1,219 * * \\
0,514 \\
51,2\end{array}$ \\
\hline & $\begin{array}{l}\mathrm{N} \\
\mathrm{R} \\
\mathrm{R}^{2} \\
\mathrm{~F}\end{array}$ & $\begin{array}{r}7860 \\
0,069 * * \\
0,005 \\
18,9\end{array}$ & $\begin{array}{r}7649 \\
0,127 * * \\
0,016 \\
63,2\end{array}$ & $\begin{array}{r}7808 \\
0,385^{* *} \\
0,148 \\
679,4\end{array}$ & $\begin{array}{r}6754 \\
0,631 * * \\
0,398 \\
2236,5\end{array}$ & $\begin{array}{r}7800 \\
0,690 * * \\
0,476 \\
3539,2\end{array}$ & $\begin{array}{r}7898 \\
0,661 * * \\
0,438 \\
3071,5\end{array}$ \\
\hline
\end{tabular}

$*$ Sig. $<0.050$

$* *$ Sig. $<0.010$

${ }^{26}$ Para observar esta cuestión debe atenderse al coeficiente de determinación $\mathrm{R}^{2}$. Este coeficiente permite saber la bondad del ajuste de los modelos de regresión empleados, esto es, qué porcentaje de varianza en los datos de la variable dependiente -apoyo expresado a los distintos objetos políicos - queda explicada por las variables independientes consideradas -la valoración de las políticas y la valoración de los procedimientos-. Para facilitar la lectura de las tablas se han colocado en las columnas los diversos objetos políticos analizados ordenados de mayor vinculación al apoyo difuso -la identidad con la comunidad política y los principios del régimen- hasta aquellos que reflejan el apoyo específico -los relativos a las instituciones y el presidente en ejercicio-. La satisfacción con el funcionamiento del Estado de las autonomías es un indicador, como el de satisfacción con la democracia que se sitúa en un punto intermedio entre ambos, pues refleja tanto cuestiones relativas al régimen como a las autoridades en ejerccio, o al menos, así se deduce la de aplicación del análisis factorial en este caso. 
Sería interesante comprobar en qué medida las percepciones sobre las políticas permitieron en los primeros años del Estado de las autonomías interpretar las variaciones en el apoyo político, pues su influencia no tiene que ser necesariamente constante a lo largo del tiempo y, mucho menos, en el caso de un nivel de gobierno que para la mayor parte del país se ha construido ex novo, y que ha supuesto la ruptura con una tradición fuertemente centralista y uniformista.

\section{B) ¿Qué nos permite explicar mejor la variación en el apoyo político, las políticas públicas o los otros factores que se han utilizado como variables de control?}

Como se ha indicado en el marco conceptual, sobre el apoyo político inciden numerosos factores además de las políticas públicas. La tabla 4 nos permite analizar cuál es el potencial que presenta cada tipo de variable para interpretar el apoyo político ${ }^{27}$. En ella se comparan cuatro bloques de variables:

- La valoración de las políticas y los procedimientos, esto es, las variables que hemos seleccionado en nuestro modelo básico para analizar la influencia de las políticas sobre el apoyo político.

- Otras variables relativas a los resultados de las políticas públicas. Aquí se incluye la valoración de la situación económica actual de la comunidad autónoma, así como los juicios retrospectivos respecto de las políticas del gobierno autonómico y de la situación económica de la comunidad autónoma ${ }^{28}$.

- Una serie de variables micro relativas a los intereses, valores y comportamientos de los individuos entre las que se incluyen el sexo, la edad, el nivel de estudios, la religiosidad, la proximidad al partido del presidente $^{29}$ y el voto al partido ganador ${ }^{30}$.

${ }^{27}$ Para poder responder a esta cuestión se ha optado por calcular y comparar los coeficientes de determinación para cada objeto político tomando únicamente como variables independientes aquellas correspondientes a un tipo de factor concreto. Así, por ejemplo, se observa cómo el porcentaje de varianza explicada por la valoración de las políticas y procedimientos sobre el apoyo al presidente autonómico en ejercicio es del 43.8 por 100, cifra sensiblemente superior a la que permiten explicar por si solos los factores micro considerados -esto es, sexo, edad, nivel de estudios, religiosidad, proximidad al partido del presidente y voto al partido ganador- sobre ese mismo objeto político, que en este caso es del 27.0 por 100.

${ }^{28}$ La inclusión de la valoración de la situación económica se ha debido a que, como comentábamos antes, constituve uno de los indicadores más aceptados por la literatura sobre el performance económico de los gobiernos. La inclusión de juicios retrospectivos obedece a que, según han mostrado diversos estudios sobre el comportamiento electoral, es importante considerar el horizonte temporal de los juicios que hacen los ciudadanos del performance de sus gobiernos. Así, se suele distinguir entre el voto económico retrospectivo, basado en los resultados pasados de las autoridades en ejercicio, el actual y el voto prospectivo, en el que se toma en consideración las expectativas económicas futuras que ofrecen los diferentes candidatos o partidos (Lewis-Beck 1988). Dado que el cuestionario del estudio Instituciones y Autonomías contiene juicios retrospectivos sobre las políticas nos ha parecido oportuno tomar en consideración este factor para ver su influencia comparativa respecto de los juicios referidos a la situación actual. Merece la pena señalar en este punto que todos los juicios sobre las políticas que hemos manejado son de carácter sociotrópico -es decir, se trata de juicios generales de carácter colectivo-; la elección era obligada, pues la fuente no contiene preguntas egocéntricas. No obstante, como ya señalaran Kinder y Kiewiet (1979 y 1981) en el caso del voto económico, al menos para el caso de los Estados Unidos de América, tendían a pesar más las consideraciones de carácter colectivo que aquellos temas que afectan de forma inmediata y tangible a la vida privada.

${ }_{29}^{2}$ La proximidad al partido del presidente ha sido un indicador que hemos construido a partir de una pregunta sobre identidad partidaria. Como es de sobra conocido, esta última es considerada por los estudios electorales como uno de los factores más importantes en la conformación del voto. Adquirida en parte a través de procesos de socialización, el voto derivado de la identidad partidaria se ha considerado tradicionalmente como un voto poco sofisticado e incluso poco racional. No obstante, la identidad partidaria refleja también una especie de atajo racional o guía que utilizan los electores para simplificar la obtención de información política asociando a determinados partidos el desarrollo de un tipo de políticas públicas concretas. En este sentido, la proximidad al partido del presidente podría utilizarse como un indicador indirecto y resumen de la distancia entre las preferencias de output de política pública de un ciudadano y su gobierno.

${ }^{30}$ Diversas investigaciones -entre otras las de Fuchs, Guidorossi y Svensson (1995); y Anderson y Guillory (1997)- han mostrado la existencia de diferencias en cuanto al grado de satisfacción con el funcionamiento de la democracia dependiendo de que se pertenezca a la mayoría o la minoría política. En este sentido, los perdedores en unas elecciones democráticas suelen mostrar niveles más bajos de satisfacción con el funcionamiento de la democracia que aquellos otros que votaron con la mayoría. 
- Una serie de variables macro relativas al entorno económico, social y político institucional, como son el PIB per capita, el \% de personas pertenecientes a asociaciones voluntarias ${ }^{31}$, el número efectivo de partidos y el índice de polarización de Sartori ${ }^{32}$, el tipo de coalición de gobierno ${ }^{33}$, la estabilidad del gobierno ${ }^{34}$ y el tiempo transcurrido desde la primera elección del presidente de la comunidad autónoma ${ }^{35}$.

TABLA 4

La influencia de distintos factores sobre el apoyo político. Coeficientes de determinación

\begin{tabular}{|l|c|c|c|c|c|c|}
\hline \multicolumn{1}{|c|}{} & $\begin{array}{c}\text { Identidad } \\
\text { con la } \\
\text { Comunidad } \\
\text { Autónoma }\end{array}$ & $\begin{array}{c}\text { Preferencias } \\
\text { de } \\
\text { organización } \\
\text { del Estado }\end{array}$ & $\begin{array}{c}\text { Satisfacción con } \\
\text { el funcionamiento } \\
\text { del Estado } \\
\text { de las autonomías }\end{array}$ & $\begin{array}{c}\text { Valoración } \\
\text { de la labor } \\
\text { del Parlamento } \\
\text { autonómico }\end{array}$ & $\begin{array}{c}\text { Valoración } \\
\text { de la labor } \\
\text { del Gobierno } \\
\text { autonómico }\end{array}$ & $\begin{array}{c}\text { Valoración } \\
\text { de la gestión } \\
\text { del Presidente } \\
\text { autonómico } \\
\text { en ejercicio }\end{array}$ \\
\hline $\begin{array}{l}\text { Valoración políticas } \\
\text { y procedimientos }\end{array}$ & 0,005 & 0,016 & 0,148 & 0,398 & 0,476 & 0,438 \\
$\begin{array}{l}\text { Otros factores } \\
\text { de políticas }\end{array}$ & 0,005 & 0,015 & 0,113 & 0,247 & 0,272 & 0,215 \\
\hline Factores micro & 0,016 & 0,025 & 0,048 & 0,184 & 0,232 & 0,270 \\
\hline Factores macro & 0,092 & 0,051 & 0,008 & 0,013 & 0,012 & 0,009 \\
\hline
\end{tabular}

${ }^{31}$ La inclusión de esta variable obedece al intento de considerar la influencia del capital social sobre el apoyo político. Según Putnam, Leonardi y Nanetti (1993), el concepto tiene dos componentes, uno de confianza social y otro de compromiso cívico con los asuntos de la comunidad. Este último es el que se intenta estimar con el indicador mencionado.

${ }^{32} \mathrm{La}$ influencia del sistema de partidos sobre el apoyo político es uno de los aspectos político-institucionales que ha recibido más atención. Según Weil (1989) cuanto más fragmentado y polarizado esté un sistema de partidos menor será el nivel de apoyo político, tanto en lo relativo a la confianza política como en aspectos más sustanciales de la legitimidad del sistema democrático. Norris (1999), por su parte, contempló las relaciones entre fragmentación del sistema de partidos y el apoyo político como una curva en forma de «u» en lugar de como una relación lineal. Así, si se dispone de un sistema de partidos de partido predominante en el que la oposición esté muy fragmentada y tenga pocas posibilidades de acceder al poder, el apoyo político tenderá a bajar ya que las posibilidades de alternancia son reducidas y con ellas los estímulos para que los partidos en el poder rindan cuentas ante los ciudadanos. En el polo opuesto, un sistema de partidos muy fragmentado y polarizado también generaría bajo apoyo político, entre otras cosas, por las dificultades para gobernar de forma estable y generar políticas con un amplio consenso social. Por el contrario, los sistemas bipartidistas y multipartidistas moderados suelen disfrutar de un mayor apoyo político. La autora mencionada encontró una asociación estadística significativa entre la confianza institucional y el sistema de partidos conforme con la hipótesis mencionada.

${ }^{33}$ Weil (1989) incorpora también algunas reflexiones sobre la influencia de las coaliciones en el apoyo político. Para este autor las coaliciones sobredimensionadas y los gobiernos en minoría -en el caso de los sistemas parlamentarios- y el gobierno dividido -en el caso de los sistemas presidencialistas-, contribuyen a la disminución del apoyo político, tanto en términos de confianza política como de legitimidad. Por el contrario, el apoyo tiende a aumentar cuando gobierna un solo partido con mayoría absoluta o cuando lo hace una coalición ganadora mínima -en el supuesto de un sistema parlamentario-, o cuando el presidente dispone de una amplia mayoría en ambas cámaras -en un sistema presidencialista-.

${ }^{34}$ La estabilidad de los ejecutivos también influye sobre el apoyo político. Harmel y Robertson (1986) encontraron una fuerte asociación entre la estabilidad gubernamental y el grado de satisfacción con el funcionamiento de la democracia. La interpretación que dieron a este hecho fue que los cambios en el ejecutivo pueden, por una parte, dañar el rendimiento de los gobiernos y, por otra, generar un sentimiento de ansiedad vinculado a la percepción de «caos en las alturas», contribuyendo ambas cosas a la pérdida de apoyo político. Weil (1989) también aporta algunas evidencias empíricas al respecto.

35 El factor tiempo ha sido una de las cuestiones señaladas por los estudios sobre la popularidad de los presidentes. Así, conforme pasa el tiempo en el gobierno, las decisiones de los ejecutivos irían generando la «coalición de los descontentos» y con ella iría bajando la valoración del presidente. 
A la pregunta de qué tipo de variables explican mejor el apoyo político, la respuesta vuelve a ser que depende del objeto político que consideremos. En lo referente a la identidad con la comunidad autónoma y las preferencias de organización del Estado, las variables relativas a las políticas públicas -ya sean las del modelo restringido o las consideradas respecto a la situación económica y los juicios retrospectivos-apenas ejercen influencia alguna, mientras que el peso de los factores del entorno tiende a ser mayor. No obstante, incluso en el caso de estos últimos la capacidad explicativa es muy reducida.

Por el contrario, desde la satisfacción con el funcionamiento del Estado de las autonomías hasta la valoración del presidente en ejercicio, son las dos variables de política pública que hemos seleccionado las que cuentan con un potencial mayor para interpretar las variaciones en el apoyo, situándose muy por encima de las variables micro que, no obstante, son de una importancia nada desdeñable en lo que respecta a las instituciones y autoridades del régimen.

Estos resultados son, nuevamente, consistentes con la teoría. Si se quiere interpretar el apoyo a la comunidad política y a los principios del régimen tendremos que recurrir a otro tipo de variables que reflejen, como indicaba Easton, la socialización y la experiencia directa de los individuos. En el caso de los sentimientos de identidad con la comunidad resulta evidente. En lo que tiene que ver con las preferencias respecto de la organización territorial del Estado, la propia posición en cuanto a los sentimientos de pertenencia a la comunidad política es una variable que indudablemente influye sobre esta cuestión. Asimismo, el progresivo crecimiento del apoyo al Estado de las autonomías, al menos en términos de opinión pública, en parte se debe a la propia experiencia y los procesos de descentralización emprendidos, que han permitido un mejor ajuste entre la estructura institucional y la cultura política de los españoles. En cualquier caso, los resultados de las políticas en el día a día poco aportan en el corto plazo para interpretar los niveles de apoyo.

En cambio, para las instituciones y las autoridades en ejercicio se comprueba la validez de la afirmación de Miller (1974b) de que las políticas públicas son un factor muy importante que influye en el apoyo político, pero no el único. Por otro lado, cuando Orren (1997) señaló que si se quería interpretar el apoyo político era mejor centrar la atención en el performance percibido del gobierno que en cualquier otro factor, con estos datos y para este caso, se comprueba la veracidad de su hipótesis.

En todo caso, conviene hacer algunas matizaciones. Téngase en cuenta que el sistema de variables de control empleado no es exhaustivo, en unos casos porque la información no está disponible en la fuente empleada -como, por ejemplo, el efecto de los medios de comunicación-; en otros, porque no se puede observar la incidencia de factores relevantes, ya sea porque se trate de elementos constantes - por ejemplo, la forma de gobierno que en todas las comunidades responde a un esquema parlamentario- o por la relativa homogeneidad de las comunidades autónomas entre sí -a pesar de que nos puedan parecer muy importantes sus diferencias internas-. Solamente adoptando un tipo de estudio comparativo más amplio, que desborde las fronteras de España, sería posible observar con nitidez el efecto de los factores del entorno, que sin duda en este caso, por el tipo de análisis realizado, están subestimados.

\section{C) ¿Qué efecto ejerce sobre el apoyo político cada una de las variables independientes tomadas en consideración de forma separada?}

Conforme se observa en la tabla $3^{36}$ la valoración de las políticas incide sobre el apoyo político en todos los objetos considerados. Su influencia es directa, de tal manera que cuanto mejor es la valoración de las políticas

${ }^{36}$ Para calibrar la influencia que cada variable independiente considerada ejerce, por separado, sobre el apovo a los distintos objetos políticos, debemos recurrir al coeficiente $b$ de regresión parcial. Este puede presentar valores positivos o negativos dependiendo de que la relación entre las variables sea directa o inversa. Los coeficientes $b$ de una misma variable independiente comparten la misma unidad de medi$\mathrm{da}$, con lo cual se pueden realizar comparaciones sobre el efecto de esa variable independiente sobre los diversos objetos políticos. Para el lector no familiarizado con la estadística conviene resaltar el hecho de que no es posible comparar los coeficientes de regresión parcial de la valoración de las políticas y los de valoración de los procedimientos ya que no comparten unidad de medida. 
mayor es el nivel de apoyo obtenido. No obstante, en el caso de la identidad con la comunidad autónoma su efecto es muy reducido, creciendo conforme nos desplazamos hacia los objetos de apoyo específico, experimentándose una ligera reducción en el caso del apoyo al presidente en ejercicio, que se encuentra por debajo del efecto ejercido por la valoración de las políticas sobre las instituciones.

En lo que respecta a la valoración de los procedimientos, es significativa en todos los objetos excepto en el apoyo a la comunidad política. Su influencia es también directa y su efecto es más intenso conforme nos desplazamos desde los objetos de apoyo difuso hacia los de apoyo específico.

\section{D) ¿Qué influye más sobre el apoyo, la valoración de los procedimientos o la de los resultados?}

Para responder a esta pregunta debemos fijarnos en los coeficientes $\beta$ estandarizados o pesos relativos ${ }^{37}$ recogidos en la tabla 3. Una vez más, la respuesta a la pregunta varía con el objeto político que consideremos. En el caso de la identificación con la comunidad autónoma, las preferencias de organización territorial y la satisfacción con el funcionamiento del Estado de las autonomías, pesan más los resultados de las políticas que los procedimientos. No obstante, recuérdese que en estos objetos políticos la influencia de las políticas sobre el apoyo es muy reducida.

Por el contrario, en el caso del apoyo hacia las instituciones y las autoridades en ejercicio la influencia de los procedimientos sobre el apoyo es mayor que la de los resultados.

Quizá pueda llamar la atención el hecho de que los procedimientos través de los cuales se gobierna importen más a efectos de apoyo que los resultados percibidos de la propia acción de gobierno. Sin embargo, cuando se toman en consideración el conjunto de variables de control seleccionadas -véase la tabla 5- se repite la misma estructura de pesos relativos en lo que concierne a las instituciones y las autoridades en ejercicio. Como medio adicional para corroborar estos resultados hemos realizado este mismo análisis por comunidades autónomas -véase la tabla 6-, dando lugar a una pauta similar.

Ahora bien, no se trata únicamente de una pauta consistente desde el punto de vista estadístico. También está en consonancia con los resultados obtenidos por investigaciones anteriores realizados en contextos muy distintos al del caso de las comunidades autónomas en España.

Así, por ejemplo, Tyler y otros (1985) en un estudio que realizaron a una pequeña muestra aleatoria de ciudadanos de Chicago en 1983, indagaron sobre la influencia que ejercían los resultados y diversos aspectos relativos a la justicia procedimental y distributiva sobre el apoyo a diversas instituciones -el Gobierno Federal, la Presidencia, el Congreso y el Tribunal Supremo-y seis líderes políticos concretos. En dicho estudio observaron que tanto la justicia como los resultados influían sobre las evaluaciones de las instituciones y de sus líderes, pero que la percepción de la justicia, tanto procedimental como distributiva, influía más que los propios resultados. Al final concluían que «los ciudadanos actúan como ingenuos filósofos morales a la hora de evaluar el gobierno, juzgando sus acciones con criterios abstractos de justicia».

Hibbing y Theiss-Morse (2001) analizaron, a través de una muestra nacional recabada en 1998, la influencia que ejercían los aspectos sustantivos de las políticas - tanto en términos de policy outputs como de policy outcomes- sobre la aprobación del gobierno federal en los Estados Unidos de América, llegando a la conclusión de que los procedimientos importaban. Eso no significaba que los aspectos relativos a los resultados y las preferencias de política pública no fueran importantes, sino que las cuestiones procedimentales también lo eran. Por otra parte, observaron que los ciudadanos estaban más insatisfechos con los aspectos procedimentales que con los aspectos sustantivos de las políticas.

\footnotetext{
${ }^{37}$ Dichos coeficientes permiten comparar la influencia que ejercen sobre un mismo objeto político la valoración de las políticas y la de los procedimientos, pues en este caso comparten unidad de medida.
} 
Desde un punto de vista teórico, los resultados de los estudios mencionados y los obtenidos en esta investigación no deberían sorprender, pues ya hace muchos años, en 1966, uno de los principales estudiosos de las políticas públicas, Dye, señalaba que «el modo en el que una sociedad asigna los valores con autoridad es más importante que el propio resultado de las asignaciones».

TABLA 5

Valoración de las politicas, valoración de los procedimientos, variables de control y apoyo político. Pesos relativos

\begin{tabular}{|c|c|c|c|c|c|c|}
\hline & $\begin{array}{l}\text { Identidad } \\
\text { con la } \\
\text { Comunidad } \\
\text { Autónoma }\end{array}$ & $\begin{array}{c}\text { Preferencias } \\
\text { de } \\
\text { organización } \\
\text { del Estado }\end{array}$ & $\begin{array}{l}\text { Satisfacción con } \\
\text { el funcionamiento } \\
\text { del Estado } \\
\text { de las autonomías }\end{array}$ & $\begin{array}{l}\text { Valoración } \\
\text { de la labor } \\
\text { del Parlamento } \\
\text { autonómico }\end{array}$ & $\begin{array}{l}\text { Valoración } \\
\text { de la labor } \\
\text { del Gobierno } \\
\text { autonómico }\end{array}$ & $\begin{array}{c}\text { Valoración } \\
\text { de la gestión } \\
\text { del Presidente } \\
\text { autonómico } \\
\text { en ejercicio }\end{array}$ \\
\hline $\begin{array}{l}\text { Valoración } \\
\text { procedimientos }\end{array}$ & 0,015 & $0,086 * *$ & $0,180^{* *}$ & $0,304 * *$ & $0,357 * *$ & $0,387 * *$ \\
\hline $\begin{array}{l}\text { Valoración } \\
\text { políticas }\end{array}$ & 0,032 & $0,087 * *$ & $0,166^{* *}$ & $0,215^{* *}$ & $0,237 * *$ & $0,138^{* *}$ \\
\hline $\begin{array}{l}\text { Situación } \\
\text { económica } \\
\text { autonómica }\end{array}$ & 0,004 & $0,061 * *$ & $0,120^{* *}$ & $0,071 * *$ & $0,077 * *$ & $0,065^{* *}$ \\
\hline $\begin{array}{l}\text { Valoración } \\
\text { políticas } \\
\text { retrospectiva }\end{array}$ & 0,018 & $-0,029$ & 0,002 & $0,069 * *$ & $0,043^{* *}$ & 0,015 \\
\hline $\begin{array}{l}\text { Situación } \\
\text { económica } \\
\text { autonómica } \\
\text { retrospectiva }\end{array}$ & $-0,024$ & 0,008 & $0,034^{*}$ & $0,032^{*}$ & $0,026^{*}$ & $0,053 * *$ \\
\hline $\begin{array}{l}\text { Proximidad } \\
\text { partido } \\
\text { presidente }\end{array}$ & 0,031 & $-0,035^{*}$ & $0,042^{* *}$ & $0,123 * *$ & $0,149 * *$ & $0,185^{* *}$ \\
\hline Sexo & 0,014 & $0,063^{* *}$ & $-0,007$ & $0,055^{* *}$ & $0,042^{* *}$ & $0,028 * *$ \\
\hline Edad & $-0,053 * *$ & $-0,097 * *$ & $-0,048^{* *}$ & $-0,028^{*}$ & $-0,023^{*}$ & $-0,014$ \\
\hline $\begin{array}{l}\text { Nivel de } \\
\text { estudios }\end{array}$ & $0,031 *$ & $-0,070 * *$ & $-0,008$ & $-0,016$ & $-0,039 * *$ & $-0,047 * *$ \\
\hline $\begin{array}{l}\text { Escala } \\
\text { religiosidad }\end{array}$ & $-0,044^{* *}$ & $0,043^{* *}$ & $-0,006$ & 0,013 & $-0,009$ & 0,011 \\
\hline $\begin{array}{l}\text { Recuerdo voto } \\
\text { autonómico } \\
\text { partido } \\
\text { presidente }\end{array}$ & 0,002 & $-0,021$ & $-0,016$ & 0,023 & $0,043^{* *}$ & $0,082^{* *}$ \\
\hline PIB per capita & $-0,240 * *$ & $-0,026$ & 0,026 & $-0,001$ & 0,004 & $0,079 * *$ \\
\hline $\begin{array}{l}\% \text { pertenencia } \\
\text { asociaciones } \\
\text { voluntarias }\end{array}$ & $-0,002$ & 0,051 & 0,025 & $0,046^{*}$ & 0,014 & $-0,003$ \\
\hline $\begin{array}{l}\mathrm{N} \text { efectivo de } \\
\text { partidos }\end{array}$ & $0,270^{* *}$ & 0,001 & $0,124^{* *}$ & 0,041 & $-0,047$ & $-0,125^{* *}$ \\
\hline $\begin{array}{l}\text { Polarización } \\
\text { Sartori }\end{array}$ & 0,029 & $-0,041 *$ & 0,000 & $-0,006$ & $-0,005$ & $-0,018$ \\
\hline Coalición & 0,049 & $0,225^{* *}$ & $0,167 * *$ & 0,064 & $-0,016$ & $-0,054$ \\
\hline $\begin{array}{l}\text { Estabilidad } \\
\text { presidente }\end{array}$ & $0,098^{* *}$ & $0,062^{* *}$ & 0,024 & $0,034^{*}$ & $0,078^{* *}$ & 0,010 \\
\hline $\begin{array}{l}\text { Tiempo } \\
\text { presidente }\end{array}$ & 0,044 & $-0,024$ & 0,036 & 0,030 & $-0,045^{* *}$ & $-0,061^{* *}$ \\
\hline $\mathrm{N}$ & 6020 & 5852 & 5954 & 5149 & 5936 & 6008 \\
\hline $\mathrm{R}$ & $0,340^{* *}$ & $0,301 * *$ & $0,409 * *$ & $0,647 * *$ & $0,714^{* *}$ & $0,709 * *$ \\
\hline $\mathrm{R}^{2}$ & 0,116 & 0,090 & 0,167 & 0,419 & 0,510 & 0,503 \\
\hline
\end{tabular}

$*$ Sig. $<0.050$

** Sig. $<0.010$ 


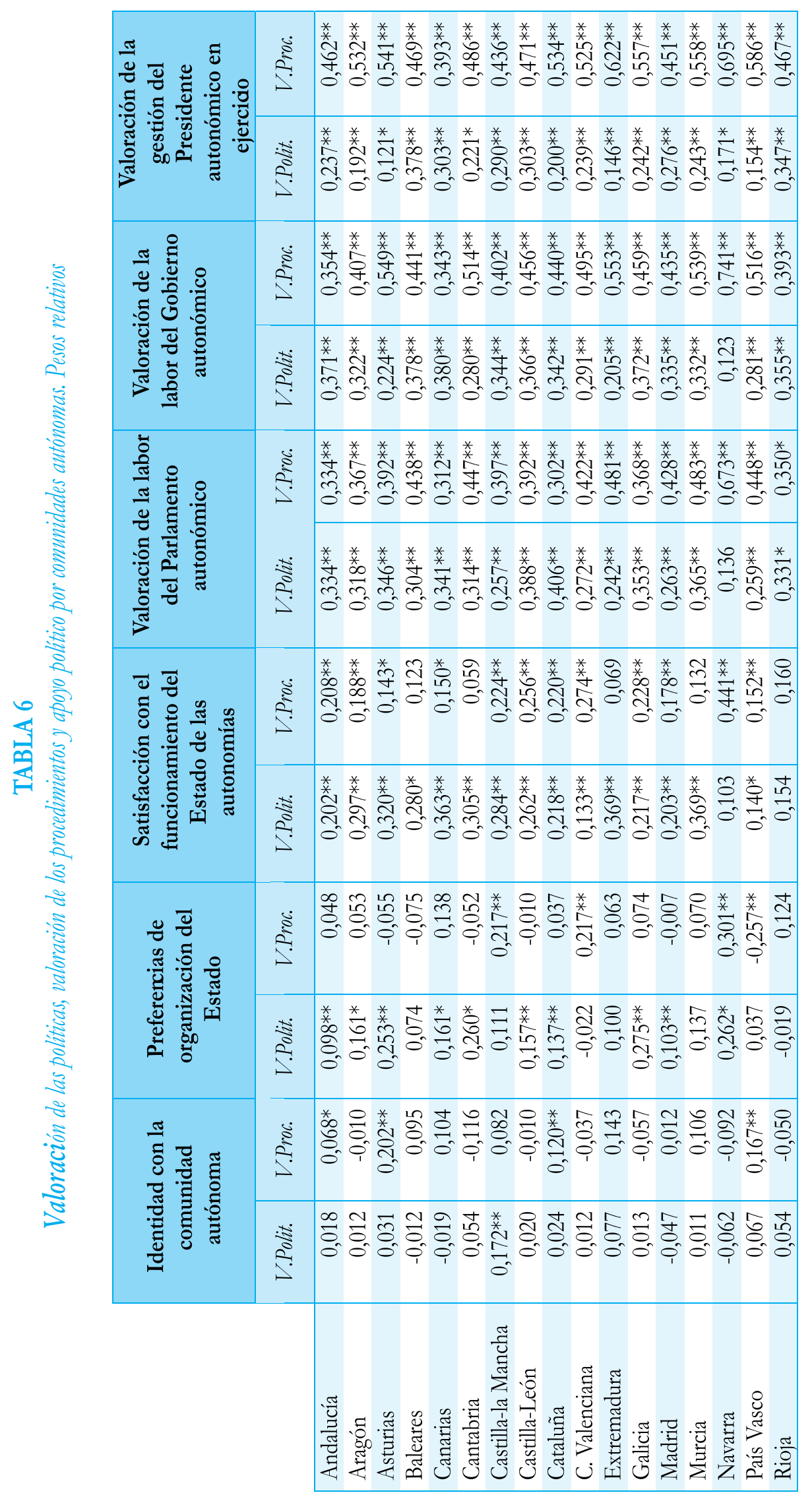




\section{Conclusiones: ¿por qué importan tanto los procedimientos?}

Inglehart (1999) ha llamado la atención sobre un hecho que merece la pena recordar y es que gobernar en las sociedades post-modernas es más difícil que en las sociedades de la escasez en las que existe una tendencia a idealizar la autoridad. La ciudadanía de las sociedades post-modernas es más crítica y exigente y somete a un escrutinio más riguroso a las autoridades e instituciones jerárquicas.

Putnam, Pharr y Dalton (2000) recogen esta línea de razonamiento y señalan que uno de los factores que influyen sobre la pérdida de confianza en las instituciones políticas es el cambio de criterios de evaluación de la política y del gobierno, de modo que se hace objetivamente más difícil para las instituciones representativas el alcanzar los estándares de performance de unos ciudadanos cada vez más exigentes.

Dalton (2000) desarrolló está tesis intentando mostrar cómo el cambio de valores en una dirección postmaterialista, supone también una transformación de los criterios con los que se juzgan a los gobiernos, incrementándose la discrepancia entre las aspiraciones de los ciudadanos y el performance gubernamental. Ello afectaría tanto a las demandas de políticas públicas como, y de una manera muy especial, al proceso de gobierno.

Si todo esto es así, y tenemos en cuenta que en las naciones desarrolladas en las que existen elevados grados de consenso en la opinión pública en los temas relativos a la vieja agenda política (Borre y Scarbrough 1995) y en las que los gobiernos suelen ser razonablemente receptivos (Page y Shapiro 1992) y eficaces (Bok 1997), es lógico que los aspectos procedimentales adquieran cada vez más relevancia. Cosa distinta es lo que pueda suceder en las naciones en desarrollo o, en el caso de las naciones desarrolladas, si se produjera un descenso sustancial y continuado, más allá de episodios esporádicos, de la receptividad y eficacia de los gobiernos.

Buena parte de la pérdida de confianza en las instituciones que se observa en muchas democracias tiene que ver con cuestiones procedimentales sobre las que centra su atención una opinión pública cada vez más sofisticada y exigente. Por otra parte, los éxitos y fracasos de muchos líderes políticos tienen más que ver con las percepciones que se forman los ciudadanos en cuanto a los modos a través de los cuales gobiernan que con los resultados de su propia acción de gobierno. Eso no significa que los resultados no importen, claro que importan, pero una vez alcanzados unos ciertos estándares importan menos que los procedimientos.

\section{REFERENCIAS BIBLIOGRÁFICAS}

Almond, G.A. (1991), The Civic Culture Revisited. Newbur Park: Sage [Traducción al castellano en R. del Águila y F. Vallespín, La democracia en sus textos. Madrid: Alianza Editorial, 1998].

Alvira, F., García, J., y Delgado, M. (2000), Sociedad, impuestos y gasto público. La perspectiva del contribuyente. Madrid: CIS.

Anderson, Ch. J. y Guillory, Ch. A. (1997), «Political Institutions and Satisfaction with Democracy: A Cross-National Analysis of Consensus and Majoritarian Systems», The American Political Science Review 91: 66-81.

Bañón, R. y Carrillo, E. (1997), «La legitimidad de la administración pública», en R. Bañón y E. Carrillo, comps., La nueva administración pública. Madrid: Alianza. 
Bazaga, I., Carrillo, E., Ramos, J.A., Sosa, J. y Tamayo, M. (1998), El consumo y la calidad de los servicios públicos: estudio de caso de la ciudad de Coslada. Madrid: Consejería de Medio Ambiente y Desarrollo Regional de la Comunidad de Madrid.

Beetham, D. (1991), The Legitimation of Power. Hong Kong: Macmillan.

Bok, D. (1997), «Measuring the Performance of Government», en J.S. Nye Jr., P.D. Zelikow, D.C. King, comps., Why People don't Trust Government. Cambridge, Mass.: Harvard University Press.

Borre, O. y Goldsmith, M. (1995), «The Scope of Government», en O. Borre, y E. Scarbrough, comps., The Scope of Government. Oxford: Oxford University Press.

Borre, O. y Scarbrough, E., comps. (1995), The Scope of Government. Oxford: Oxford University Press.

Bouza, F. (2004a), «Las agendas pública y personal en el tema del Prestige». Pontevedra: Universidad de Vigo.

Bouza, F. (2004b), «The impact area of political communication: citizenship faced with public discourse», International Review of Sociology 14, 2: 245-259.

Carrillo, E. (1996-97), «Legitimidad y modernización de la administración pública», Gestión y Análisis de Políticas Públicas 7-8: 143152.

Carrillo, E. y Tamayo, M. (2002), «La legitimidad de la administración pública: un enfoque de cultura política», Foro Internacional 170: $683-715$.

Carrillo, E., Tamayo, M., Del Pino, E. y Bazaga, I. (1999-2000), Informe final del proyecto de investigación «Imagen de las administraciones y calidad de los servicios públicos en la Comunidad de Madrids. Madrid: Consejería de Educación de la Comunidad de Madrid.

Citrin, J. (1974), «Comment: The Political Relevance of Trust in Government», The American Political Science Review 68: 973-988.

Clarke, H.D., Dutt, N. y Kornberg, A. (1993), «The Political Economy of Attitudes toward Polity and Society in Western European Democracies», The Journal of Politics 55: 998-1021.

Cobb, R., Ross, J.K. y Ross, M.H. (1976), «Agenda Building as a Comparative Political Process», The American Political Science Review 70: 126-138.

Dalton, R.J. (1996), Citizens Politics. Public Opinion and Political Parties in Advanced Western Democracies. Chatham: Chatham House.

Dalton, R.J. (1999), «Political Support in Advanced Industrial Democracies», en P. Norris, comp., Critical Citizens. Global Support for Democratic Governance. Oxford: Oxford University Press.

Dalton, R.H. (2000), «Value Change and Democracy», en S. J. Pharr y R.D. Putnam, comps., Disaffected Democracies. What's Troubling the Trilateral Countries? Princeton: Princeton University Press.

Deth, J.W. van y Scarbrough, E., comps. (1995), The Impact of Values. Oxford: Oxford University Press.

Dye, T.R. (1966), Politics, Economics, and the Public. Policy Outcomes in the American States. Chicago: Rand McNally.

Easton, D. (1965), A Systems Analysis of Political Life. Nueva York: John Wiley.

Easton, D. (1975), «A Re-Assessment of the Concept of Political Support», British Journal of Political Science 5: 435-457.

Finkel, S.E., Muller, E.N. y Seligson, M.A. (1989), «Economic Crisis, Incumbent Performance and Regime Support: A Comparison of Longitudinal Data from West Germany and Costa Ricay, British Journal of Political Science 19: 329-351.

Fuchs, D., Guidorossi, G. y Svensson, P. (1995), «Support for the Democratic System», en H-D. Klingemann y D. Fuchs, Citizens and the State. Oxford: Oxford University Press.

Gronke, P. y Newman, B. (2000), «FDR to Clinton, Mueller to ?? A 'State of the Discipline' Review of Presidential Approval», Comunicación presentada en el Annual Meeting of the American Political Science Association.

Harmel, R. y Robertson, J.D. (1986), «Government Stability and Regime Support: A Cross-National Analysis», The Journal of Politics 48: 1029-1040. 
Hibbing, J.R. y Theiss-Morse, E., comps. (2001a), What is it about Government that Americans Dislike? Cambridge: Cambridge University Press.

Hibbing, J.R. y Theiss-Morse, E. (2001b), «Process Preferences and American Politics: What the People Want Government to Be», The American Political Science Review 95: 145-152.

Inglehart, R. (1971), «The Silent Revolution in Europe: Intergenerational Change in Post-Industrial Societies», The American Political Science Review 65: 991-1017.

Inglehart, R. (1997a), Modernization and Postmodernization: Cultural, Economic, and Political Change in 43 Societies. Princeton: Princeton University Press.

Inglehart, R. (1997b), «Postmaterialist Values and the Erosion of Institutional Authority», en J.S. Nye Jr., P.D. Zelikow y D.C. King, comps., Why People don't Trust Government. Cambridge, Mass.: Harvard University Press.

Inglehart, R. (1999), «Postmodernization Erodes Respect for Authority, but Increases Support for Democracy», en P. Norris, comp., Critical Citizens. Global Support for Democratic Governance. Oxford: Oxford University Press.

Kaase, M. y Newton, K. (1995), Beliefs in Government. Oxford: Oxford University Press.

Kaufman, D., Kraay, A. y Mastruzzi, M. (2005), Governance Matters IV: Governance Indicators for 1996-2004. Washington, D.C.: Banco Mundial.

Kinder, D.R. y Kiewiet, D.R. (1979), «Economic Discontent and Political Behavior: The Role of Personal Grievances and Collective Economic Judgments in Congressional Voting», The American Political Science Review 23: 495-527.

Kinder, D.R. y Kiewiet, D.R. (1981), «Sociotropic Politics: The American Case», British Journal of Political Science 11: 129-161.

Klingemann, H-D. (1999), «Mapping Political Support in the 1990s: A Global Analysis», en P. Norris, comp., Critical Citizens. Global Support for Democratic Governance. Oxford: Oxford University Press.

Klingemann, H-D. y Fuchs, D., comps. (1995), Citizens and the State. Oxford: Oxford University Press.

Lewis-Beck, M.S. (1988), «Economics and the American Voter: Past, Present, Future», Political Bebavior 10: 5-21.

Lipset, S.M. (1959), «Some Social Requisites of Democracy: Economic Development and Political Legitimacy», The American Political Science Review 53: 69-105.

Lipset, S.M. y Schneider, W. (1987), The Confidence Gap: Business, Labor, and Government in the Public Mind. Baltimore: Johns Hopkins University Press.

Listhaug, O. y Wiberg, M. (1995), «Confidence in Political and Private Institutions», en H-D. Klingemann y D. Fuchs, comps., Citizens and the State. Oxford: Oxford University Press.

Maravall, J.M. y Przeworski, A. (1998), «The Reactions to the Economy: The Spanish Experience», Working Papers 127, Fundación Juan March.

McAllister, I. (1999), «The Economic Performance of Governments», en P. Norris, comp., Critical Citizens. Global Support for Democratic Governance. Oxford: Oxford University Press.

Miller, A.H. (1974a), «Political Issues and Trust in Government: 1964-1970», The American Political Science Review 68: 951-972.

Miller, A.H. (1974b), «Rejoinder to 'Comment' by Jack Citrin: Political Discontent or Ritualism?», The American Political Science Review 68: 989-1001.

Miller, A.H. y Listhaug, O. (1990), «Political Parties and Confidence in Government: A Comparison of Norway, Sweden and the United Status», British Journal of Political Science 20: 357-386.

Montero, J.R. y Torcal, M. (1990), «Autonomías y Comunidades Autónomas en España: preferencias, dimensiones y orientaciones políticas», Revista de Estudios Politicos 70: 33-91. 
Mota, F. (1998), «Cultura política y opinión pública en las Comunidades Autónomas: un examen del sistema político autonómico en España (1984-1996)», Working Paper 153, Universitat Autònoma de Barcelona.

Mota, F. (2002), «El capital social de las autonomías: ¿Explica el capital social por qué unas comunidades autónomas funcionan mejor que otras?», en J. Subirats y R.. Gallego, comps., Veinte años de autonomias en España. Leyes, politicas priblicas, instituciones y opinión pública. Madrid: CIS.

Mota, F. y Subirats, J. (2000), «El quinto elemento: el capital social de las Comunidades Autónomas», Revista Española de Ciencia Politica 2: 123-158.

Muller, E.N. y Jukam, T.O. (1977), «On the Meaning of Political Support», The American Political Science Review 71: 1561-1595.

Muller, E.N., Jukam, T.O. y Seligson, M.A. (1982), «Diffuse Political Support and Antisystem Political Behavior: A Comparative Analysis», American Journal of Political Science 26: 240-264.

Newton, K. (1999), «Social and Political Trust in Established Democracies», en P. Norris, comp., Critical Citizens. Global Support for Democratic Governance. Oxford: Oxford University Press.

Newton, K. y Norris, P. (2000), «Confidence in Public Institutions: Faith, Culture, or Performance?», en S.J. Pharr y R.D. Putnam, comps., Disaffected Democracies. What's Troubling the Trilateral Countries? Princeton: Princeton University Press.

Nierdermayer, O. y Sinnott, R. (1995), Public opinion and Internationalized Governance. Oxford: Oxford University Press.

Norris, P., comp. (1999), Critical Citizens. Global Support for Democratic Governance. Oxford: Oxford University Press.

Norris, P. (1999), «Introduction: The Grow of Critical Citizens?», en P. Norris, comp. Critical Citizens. Global Support for Democratic Governance. Oxford: Oxford University Press.

Norris, P. (1999), «Institutional Explanations for Political Support», en P. Norris, comp. Critical Citizens. Global Support for Democratic Governance. Oxford: Oxford University Press.

Norris, P. (2000), «The Impact of Television on Civic Malaise», en S. J. Pharr y R. D. Putnam, comps., Disaffected Democracies. What's Troubling the Trilateral Countries?. Princeton: Princeton University Press.

Noya, J. (2004), Ciudadanos ambivalentes: actitudes ante la igualdad y el Estado de bienestar en España. Madrid: CIS.

Orren, G. (1997), «Fall from Grace: The Public’s Loss of Faith in Government», en J.S. Nye Jr., P.D. Zelikow, D.C. King, comps., Why People don't Trust Government. Cambridge: Harvard University Press.

Page, B.I. y Shapiro, R.Y. (1992), The Rational Public. Fifty Years of Trends in Americans' Policy Preferences. Chicago: University of Chicago Press.

Pharr, S.J. (2000), «Officials' Misconduct and Public Distrust: Japan and the Trilateral Democracies», en S. J. Pharr y R. D. Putnam, comps., Disaffected Democracies. What's Troubling the Trilateral Countries? Princeton: Princeton University Press.

Pharr, S. J. y Putnam, R. D. (2000), «Preface», en S. J. Pharr y R. D. Putnam, comps., Disaffected Democracies. What's Troubling the Trilateral Countries? Princeton: Princeton University Press.

Pino, E del (2004), Los ciudadanos y el Estado: las actitudes de los españoles hacia las Administraciones y las Politicas Públicas. Madrid: INAP.

Porta D. della (2000), «Social Capital, Beliefs in Government, and Political Corruption», en S. J. Pharr y R. D. Putnam, comps., Disaffected Democracies. What's Troubling the Trilateral Countries? Princeton: Princeton University Press.

Putnam, R.D., Pharr, S.J. y Dalton, R. J. (2000), «Introduction: What's Troubling the Trilateral Democracies?», en S. J. Pharr, y R. D. Putnam, comps., Disaffected Democracies. What's Troubling the Trilateral Countries? Princeton: Princeton University Press.

Putnam, R.D. (1995), «Tuning In, Tuning Out: The Strange Disappearance of Social Capital in America», Political Science and Politics 28: 664-683.

Putnam, R.D., Leonardo, R. y Nanetti, R.Y. (1993), Making Democracy Work. Civic Traditions in Modern Italy. Princeton: Princeton University Press. 
Tamayo, M. y Carrillo, E. (2004), «La agenda pública en España», Revista Internacional de Sociología 38: 35-59.

Tyler, T.R., Rasinski, K.A. y McGraw, K.M. (1985), «The Influence of Percived Injustice on the Endorsement of Political Leaders», Journal of Applied Social Psychology 15: 700-725.

Tyler, T.R., Boeckmann, R.J., Smith, H.J. y Huo, Y.J. (1997), Social Justice in a Diverse Society. Boulder: Westview Press.

Wahlke, J.C. (1971), «Policy Demands and System Support: The Role of the Represented», British Journal of Political Science 1: 271290.

Weil, F.D. (1989), «The Sources and Structure of Legitimation in Western Democracies: A Consolidated Model Tested with Time-Series Data in Six Countries Since World War II», American Sociological Review 54: 682-706. 